\title{
The Quest for a Truly Universal Influenza Vaccine
}

\author{
Yo Han Jang ${ }^{1 \dagger}$ and Baik Lin Seong ${ }^{1,2 *}$ \\ ${ }^{1}$ Molecular Medicine Laboratory, Department of Biotechnology, College of Life Science and Biotechnology, Yonsei University, \\ Seoul, South Korea, ${ }^{2}$ Vaccine Translational Research Center, Yonsei University, Seoul, South Korea
}

OPEN ACCESS

Edited by:

Yanmin Wan

Fudan University, China

Reviewed by:

Peter Palese,

Icahn School of Medicine at Mount

Sinai, United States

Florian Krammer,

Icahn School of Medicine at Mount

Sinai, United States

${ }^{*}$ Correspondence:

Baik Lin Seong

blseong@yonsei.ac.kr

tPresent address:

Yo Han Jang,

Department of Biological Sciences and Biotechnology Major in

Bio-Vaccine engineering, Andong

National University, Andong,

South Korea

Specialty section:

This article was submitted to

Clinical Microbiology,

a section of the journal

Frontiers in Cellular and Infection

Microbiology

Received: 24 May 2019 Accepted: 24 September 2019

Published: 10 October 2019

Citation: Jang YH and Seong BL (2019) The Quest for a Truly Universal Influenza

Vaccine.

Front. Cell. Infect. Microbiol. 9:344. doi: 10.3389/fcimb.2019.00344
There is an unmet public health need for a universal influenza vaccine (UIV) to provide broad and durable protection from influenza virus infections. The identification of broadly protective antibodies and cross-reactive $T$ cells directed to influenza viral targets present a promising prospect for the development of a UIV. Multiple targets for cross-protection have been identified in the stalk and head of hemagglutinin (HA) to develop a UIV. Recently, neuraminidase (NA) has received significant attention as a critical component for increasing the breadth of protection. The HA stalk-based approaches have shown promising results of broader protection in animal studies, and their feasibility in humans are being evaluated in clinical trials. Mucosal immune responses and cross-reactive T cell immunity across influenza $A$ and $B$ viruses intrinsic to live attenuated influenza vaccine (LAIV) have emerged as essential features to be incorporated into a UIV. Complementing the weakness of the stand-alone approaches, prime-boost vaccination combining HA stalk, and LAIV is under clinical evaluation, with the aim to increase the efficacy and broaden the spectrum of protection. Preexisting immunity in humans established by prior exposure to influenza viruses may affect the hierarchy and magnitude of immune responses elicited by an influenza vaccine, limiting the interpretation of preclinical data based on naive animals, necessitating human challenge studies. A consensus is yet to be achieved on the spectrum of protection, efficacy, target population, and duration of protection to define a "universal" vaccine. This review discusses the recent advancements in the development of UIVs, rationales behind cross-protection and vaccine designs, and challenges faced in obtaining balanced protection potency, a wide spectrum of protection, and safety relevant to UIVs.

Keywords: influenza virus, universal influenza vaccine, cross-protection, HA stalk, M2e, T cell, live attenuated influenza vaccine

\section{INTRODUCTION}

Influenza viruses present a high level of antigenic diversity and variability due to their segmented RNA genome. These viruses are classified into four major types, A, B, C, and $\mathrm{D}$, based on their nucleoprotein (NP) and matrix (M) genes. Human infecting type A and $\mathrm{B}$ viruses are further classified into multiple subtypes or lineages, respectively, depending on the antigenicity of viral surface proteins, hemagglutinin (HA), and neuraminidase (NA) genes (Paules and Subbarao, 2017). Influenza A and B viruses co-circulate in every season and, thus, c represents the primary targets of seasonal influenza vaccines (Sridhar et al., 2015). In addition to seasonal epidemics, influenza viruses have caused pandemics at the intervals 
of 10-40 years since the 1918 Spanish flu H1N1, the 2009 pandemic H1N1 being the last outbreak (Saunders-Hastings and Krewski, 2016). While vaccination remains the most cost-effective measure to prevent influenza virus infections, antigenic drift in the surface antigens allows these viruses to escape antibody-mediated neutralization (Kim et al., 2018a). In addition, the sudden occurrence of pandemics is often accompanied by zoonotic spillover of the surface genes into the human-infecting viruses, rendering preexisting vaccines ineffective to newly emerging viruses. The variation caused by genetic drift and shift is unpredictable, posing a serious challenge to the management of influenza outbreak. Based on the amino acid sequences of HAs, influenza A viruses (IAVs) are divided into two phylogenetic groups. The IAV HA group 1 viruses include $\mathrm{H} 1, \mathrm{H} 2, \mathrm{H} 5, \mathrm{H} 6, \mathrm{H} 8, \mathrm{H} 9, \mathrm{H} 11, \mathrm{H} 12, \mathrm{H} 13, \mathrm{H} 16, \mathrm{H} 17$, and $\mathrm{H} 18$, while the group 2 viruses comprise $\mathrm{H} 3, \mathrm{H} 4, \mathrm{H} 7, \mathrm{H} 10$, H14, H15 (Figure 1). The NAs of IAVs are also antigenically diverse, presenting two distinct groups. Influenza $B$ viruses (IBVs) are not divided into subtypes but circulate as two distinct Yamagata-like and Victoria-like lineages. Influenza $\mathrm{C}$ viruses (ICVs) generally cause a mild respiratory disease in humans and do not cause epidemics (Dykes et al., 1980). Contemporary influenza epidemics are caused by the H1N1 and H3N2 of the IAVs and one or two lineages of the IBVs, dictating trivalent (TIV) or quadrivalent influenza vaccine (QIV) containing two IAV antigens and one or two IBV antigens, respectively (Ambrose and Levin, 2012).

Many strategies have been undertaken on the pursuit of developing a universal influenza vaccine (UIV) (Paules et al., 2017). The induction of cross-protective immune responses directed toward conserved $\mathrm{B}$ cell or $\mathrm{T}$ cell epitopes is a major principle underlying broad protection (Figure 2). The direct binding of antibodies to the viral surface proteins interferes with their functions and results in virus neutralization before cell entry (Figure 2A). Alternatively, the antibodies may bind to viral antigens displayed on the surface of virus-infected cells and mediate effector functions to remove the infected cells. A cytotoxic T lymphocyte (CTL) can kill the virus-infected cells in an independent manner (Figure 2B). Several conserved viral antigens such as M2 extracellular domain (M2e), HA stalk and receptor binding site, $\mathrm{NA}$, and $\mathrm{T}$ cell epitopes in the internal proteins such as polymerase basic protein 1 (PB1), NP, and M1 were defined as targets for eliciting cross-reactive immune response. A variety of vaccine platforms were tested for effective exposure of those antigens to the immune system (Wang et al., 2018a; Estrada and Schultz-Cherry, 2019). While these vaccines showed broader cross-protection than the classical inactivated influenza vaccines (IIVs), their protection potency was weak. They provided partial protection against the antigenically distant viruses, and the protection breadth is usually limited to the same group (subtype-specific or HA group-specific) and not effective in another HA group. Thus, there exists a considerable gap between the current status, and the ultimate goal, of a truly universal vaccine.

Some studies have discovered rare antibodies specific to the conserved HA stalk in animals and humans with prior exposure to influenza viruses. Some of these antibodies show extremely broad specificity, encompassing both HA groups of IAVs (Ekiert et al., 2011) or even both IAVs and IBVs (Dreyfus et al., 2012), representing an optimistic prospect of developing a UIV. However, no studies so far have reported a successful vaccine approach that induces such antibodies to a protective level, reflecting considerable difficulty in selectively inducting particular antibodies in the context of vaccination. While antibody-dependent effector mechanisms and $\mathrm{T}$ cell immunity have emerged as potential correlates of broad protection against influenza infections (Krammer and Palese, 2015), the exact molecular mechanisms of their protective action are not completely understood, and immunopathology by $\mathrm{T}$ cell responses still remains a challenge (Peiris et al., 2010; Duan and Thomas, 2016; Erbelding et al., 2018). Moreover, understanding how preexisting immunity (immune imprinting or antigenic sinlike phenomenon) shaped by prior exposure to influenza viruses affects the magnitude, hierarchy, and sustainability of antibody response to vaccination is suggested as critical for designing a UIV in humans (Henry et al., 2018). The involvement of multiple factors in eliciting broad protection and the influence of pre-existing immunity on the subsequent vaccination pose a dilemma on establishing the correlate of cross-protection against heterologous or hetero-subtypic viruses, representing a critical obstacle for the licensure of a UIV by the regulatory authorities.

This review updates the recent advances in UIV development and focuses on the critical issues to be addressed in designing a 'truly' UIV. Alternative vaccine antigens and vaccine strategies for durable and broader protection are also discussed in detail. This review is meant to help the readers to acquire general information on the cutting edge of UIV researches and to gain wide perspectives on rational design of a truly UIV with improved potency, breadth, and safety.

\section{CRITERIA FOR A UIV}

\section{Definition of Universal Protection}

Although there is a clear consensus about the urgent need for a vaccine that provides durable and broad protection against multiple strains of influenza virus, the definition of the "universality" of UIV is still debated (Krammer et al., 2018b). Recently, the National Institute of Allergy and Infectious Diseases (NIAID) held a meeting to identify and develop the criteria to define a UIV. The participants from multiple disciplines agreed that a reasonable UIV should be at least $75 \%$ effective against symptomatic influenza virus infection caused by group 1 and group 2 IAVs, with the protection lasting over 1 year for all age groups (Paules et al., 2017; Erbelding et al., 2018) (Table 1). Similar criteria have also been suggested as preferred product characteristics (PPC) and target product profiles (TPP), describing the desired characteristics of a UIV, by the World Health Organization (WHO) and the Bill and Melinda Gates Foundation (BMGF), respectively (Table 1). Despite the priority given to IAVs in WHO PPC (Table 1), the IBVs represent a "low hanging fruit" because of their low antigenic diversity and the lack of animal reservoir, presenting credence to potential eradication from humans (Tan et al., 2018). The proposed consensus to define universal protection 


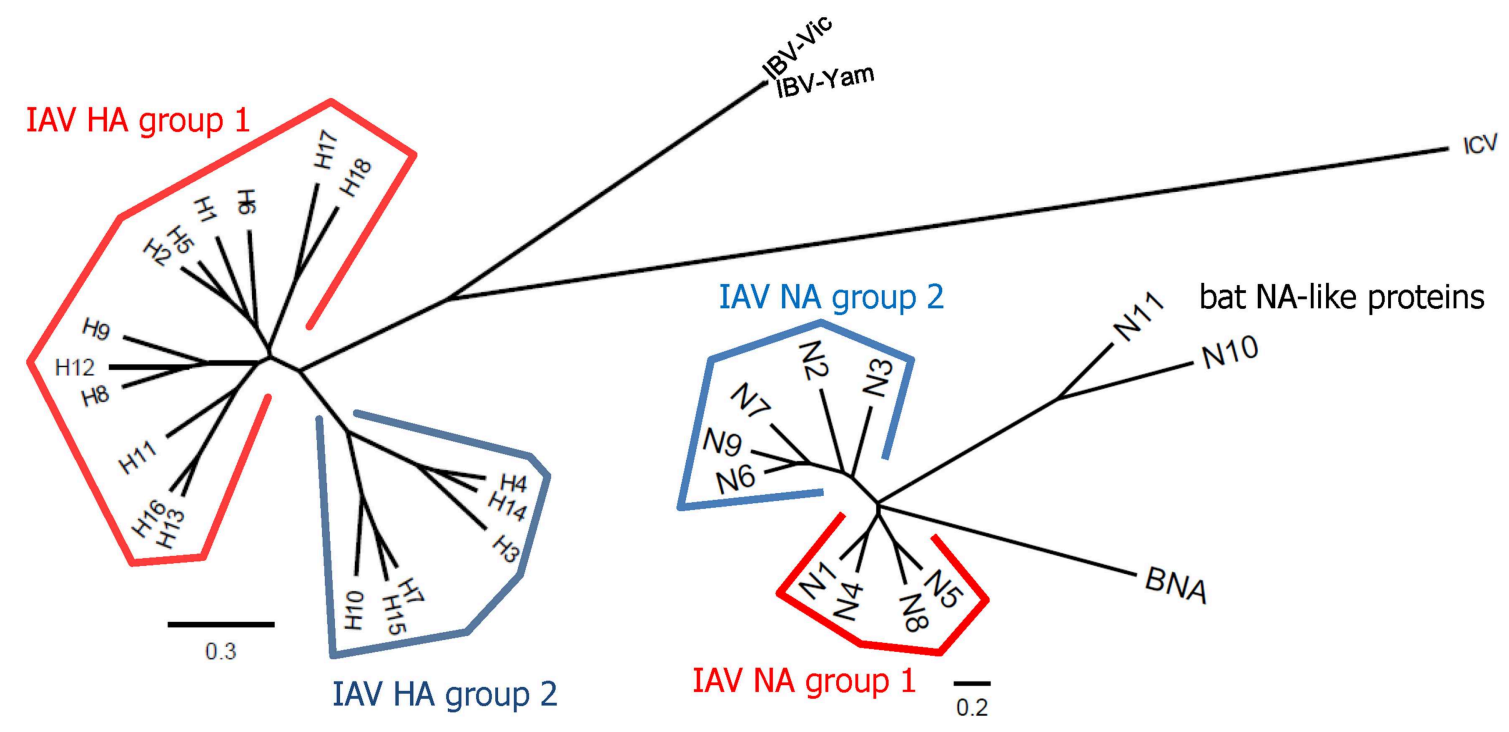

FIGURE 1 | Phylogenetic trees representing HA and NA diversity among influenza viruses. The 18 subtypes of HAs of IAV are divided into two phylogenetic groups according to their amino acid sequences similarities. The HAs of IBVs are divided into Victoria-like and Yamagata-like lineages but they are closer to each other than any of two different subtypes of IAVs. The HAs of ICVs are antigenically distant from those of IAVs and IBVs. The NAs of IAVs also show high levels of antigenic variability and are divided into two groups. Phylogenetic trees were constructed based on amino acid sequence comparisons among influenza viruses. Multiple alignments were carried out using the representative sequence of each HA or NA subtype or lineage. The phylogenetic trees were constructed by the ClustalW algorithm using neighbor joining (N-J) method and visualized by FigTree v1.4.4. The scale bars represent amino acid change (\%).

A

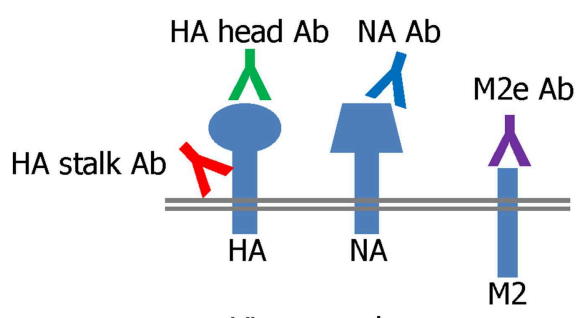

Virus membrane or infected cell membrane

\section{B}

CTLS specific to epitopes of internal proteins

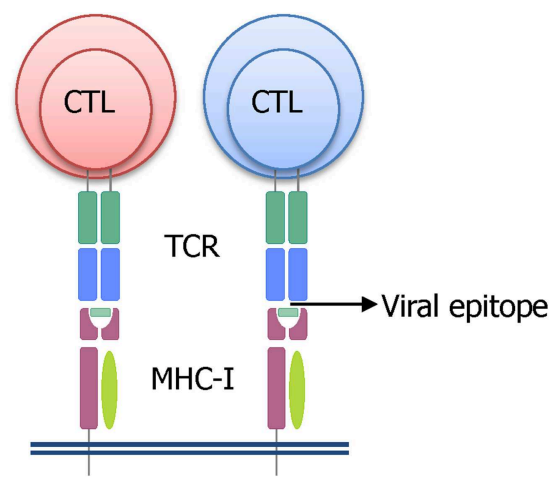

Infected cell membrane

FIGURE 2 | Major principles of developing a UIV. (A) Induction of broadly protective antibodies specific to conserved regions in the HA stalk or head, NA, or M2e has been extensively investigated. The antibodies bind to viral surface proteins either on virion or expressed on virus-infected cell membrane. (B) Cytotoxic T lymphocyte (CTL) recognizing the conserved epitopes of influenza internal proteins such as NP, M1, or PB1 has been shown to be critical for broad protection through the clearance of the virus-infected cells.

offers a valuable guideline to develop an effective and safe UIV. Ideally, the spectrum of protection may covers both IAVs and IBVs, considering the existence of extremely broadly protective antibodies and $\mathrm{T}$ cell epitopes across IAVs and IBVs from animals and humans (Corti et al., 2011; Koutsakos et al., 2019). However, as the antigenic difference between a vaccine and a target virus becomes larger, the number of conserved $\mathrm{B}$ cell or $\mathrm{T}$ cell epitopes between the two strains decreases. The limited availability of target epitopes may result in compromised protection robustness due to (1) decreased clonal diversity of cross-reactive antibodies 
TABLE 1 | Consensus criteria for a UIV.

\begin{tabular}{|c|c|c|c|c|}
\hline & NIAID & WHO & BMGF & Consensus \\
\hline Breadth & $\begin{array}{l}\text { All influenza A viruses (influenza B } \\
\text { protection would be the second } \\
\text { target) }\end{array}$ & All influenza A viruses & All influenza $A$ and $B$ viruses & All influenza A viruses \\
\hline Efficacy & $\begin{array}{l}\text { At least } 75 \% \text { effective against } \\
\text { symptomatic influenza infection }\end{array}$ & $\begin{array}{l}\text { Better than that of current seasonal } \\
\text { influenza vaccine }\end{array}$ & $\begin{array}{l}\text { At least } 70 \% \text { effective against } \\
\text { symptomatic influenza infection }\end{array}$ & At least $70 \%$ effective \\
\hline $\begin{array}{l}\text { Target } \\
\text { population }\end{array}$ & All age groups & $\begin{array}{l}>6 \text { weeks, no upper age limit } \\
\text { including high risk groups }\end{array}$ & $\begin{array}{l}>6 \text { weeks, no upper age limit } \\
\text { including high risk groups }\end{array}$ & $\begin{array}{l}>6 \text { weeks, no upper } \\
\text { age limit }\end{array}$ \\
\hline $\begin{array}{l}\text { Duration of } \\
\text { protection }\end{array}$ & At least 1 year & At least 5 years & $3-5$ years & At least 1 year \\
\hline
\end{tabular}

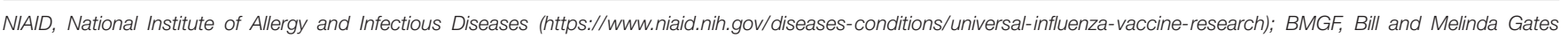

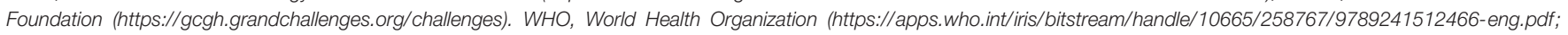
https://jsessionid=37D9E056C3EA58A90EE237432AA7D65F? sequence=1).

and $\mathrm{T}$ cells, or (2) occurrence of escape mutants by even small amount of genetic mutations in the epitopes. Therefore, a balanced breadth and robustness of cross-protection should be considered when developing a reliable UIV (Figure 3).

The NIAID and the researchers have proposed three research areas to address the knowledge gaps in developing a UIV; (1) understanding of influenza transmission, natural history, and viral pathogenesis, (2) characterization of correlates of protection, and (3) rational design of a UIV to improve potency and breadth of protection (Erbelding et al., 2018). In particular, the correlates of protection elicited by a UIV may vary considerably in quantity and quality, depending on the vaccine type used and the target influenza virus tested. For instance, while the protection potency of HA stalk-based vaccine may easily be evaluated by measuring the neutralizing activity or indirect effector mechanisms by the stalk-reactive antibodies (Jegaskanda et al., 2017b), such correlates of protection cannot be used to evaluate the protective efficacy of a T cell epitope-based vaccine containing non-HA epitopes. Moreover, when using HA stalk-based vaccines, high levels of stalk-reactive antibodies represent a good protective efficacy against the same group IAVs (Figure 1). However, the binding affinities of HA stalk antibodies are variable among different viruses, and therefore may require different antibody titers to exhibit sufficient protection against the viruses. This speculation is supported by the observations that broadly reactive HA stalk antibodies show considerably different neutralizing abilities and binding affinities to the viruses within the same HA group (Ekiert et al., 2011, 2012). Furthermore, HA stalk-based vaccine and M2e-based vaccine may demonstrate a different balance of protective abilities to each other, between direct neutralization and indirect effector mechanisms (ADCC, for instance) by the respective antibodies. It has been shown that $\mathrm{M} 2 \mathrm{e}$ antibodies provide protection via FcR-dependent effector functions rather than direct virus neutralization (Deng et al., 2015a), whereas HA stalk antibodies exert both direct neutralization and indirect effector functions (Krammer and Palese, 2015). The antibody-mediated inhibition of virus attachment measured by hemagglutinin inhibition assay or microneutralization assay is the gold standard for seasonal influenza vaccines (Ohmit et al., 2011). However, the assay cannot be applied simply to reflect the cross-protection by a UIV against heterologous/heterosubtypic influenza viruses. Therefore, it is essential to develop mechanistically distinct in vitro or in vivo assays to measure potential correlates of protection in order to evaluate the protection potency and breadth of the vaccine.

\section{Mode of Protection by a UIV}

The cornerstone of developing a UIV is the determination of the precise protection mechanisms of immune response against influenza viruses. Influenza HA recognizes sialic acid on the cellular receptors and initiates infection by entering the cell via receptor-mediated endocytosis (Figure 4). While HA inhibitory (HAI) antibodies have long been considered as the gold standard for strain-specific protection, very few of them were shown to elicit a broad protection by binding to the conserved receptor-binding site (RBS) of HA, thereby preventing viral entry to the cell (Krause et al., 2011; Ekiert et al., 2012). Recently, multifunctional protection mechanisms have been described for HA stalk-reactive antibodies. It has been shown that HA stalk antibodies may inhibit membrane fusion, the release of viral genome into the cytoplasm of the cell, and maturation of the HA precursor (Krammer and Palese, 2015). Furthermore, HA stalk antibodies can induce antibodydependent effector functions such as antibody-dependent cellular cytotoxicity (ADCC), antibody-dependent cellular phagocytosis (ADCP), and complement-dependent cytolysis (CDC), resulting in clearance of virus-infected cells by the immune cells or the complement system (Jegaskanda et al., 2017b). During viral budding, NA cleaves the sialic acid from HA and supports multiple infection cycles by release of the newly assembled viral particles. NA inhibitory (NAI) antibodies specific to the conserved regions have shown an exceptional breadth, inhibiting divergent influenza viruses (Chen et al., 2018). In addition to the broadly protective antibodies, $\mathrm{T}$ cell immunity against conserved viral internal proteins also provides a broad protection. Crossreactive cytotoxic $\mathrm{T}$ lymphocytes (CTLs) recognize the viral epitopes presented on MHC molecules and kill the infected cells. It is noteworthy that the cross-reactivity of $\mathrm{T}$ cell immunity has been recently shown to cover both IAVs and IBVs, and even the ICVs (Koutsakos et al., 2019), although its protective role in vivo has not been confirmed. 


\section{Protection coverage}

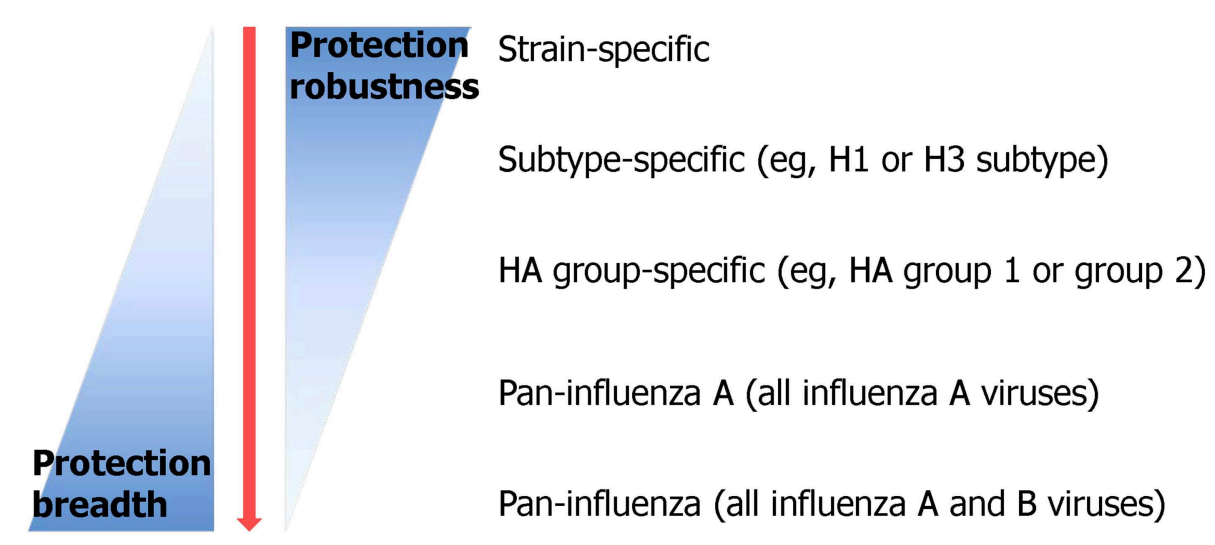

FIGURE 3 | Protection breadth of influenza vaccines ranging from strain-specific protection to pan-influenza universal protection. Currently licensed seasonal influenza vaccine provides only strain-specific protection against well-matched strains. Recently, many efforts have been put in order to improve the protection breadth of a vaccine from subtype-specific protection to, ideally, pan-influenza universal protection [adopted from Erbelding et al. (2018)].

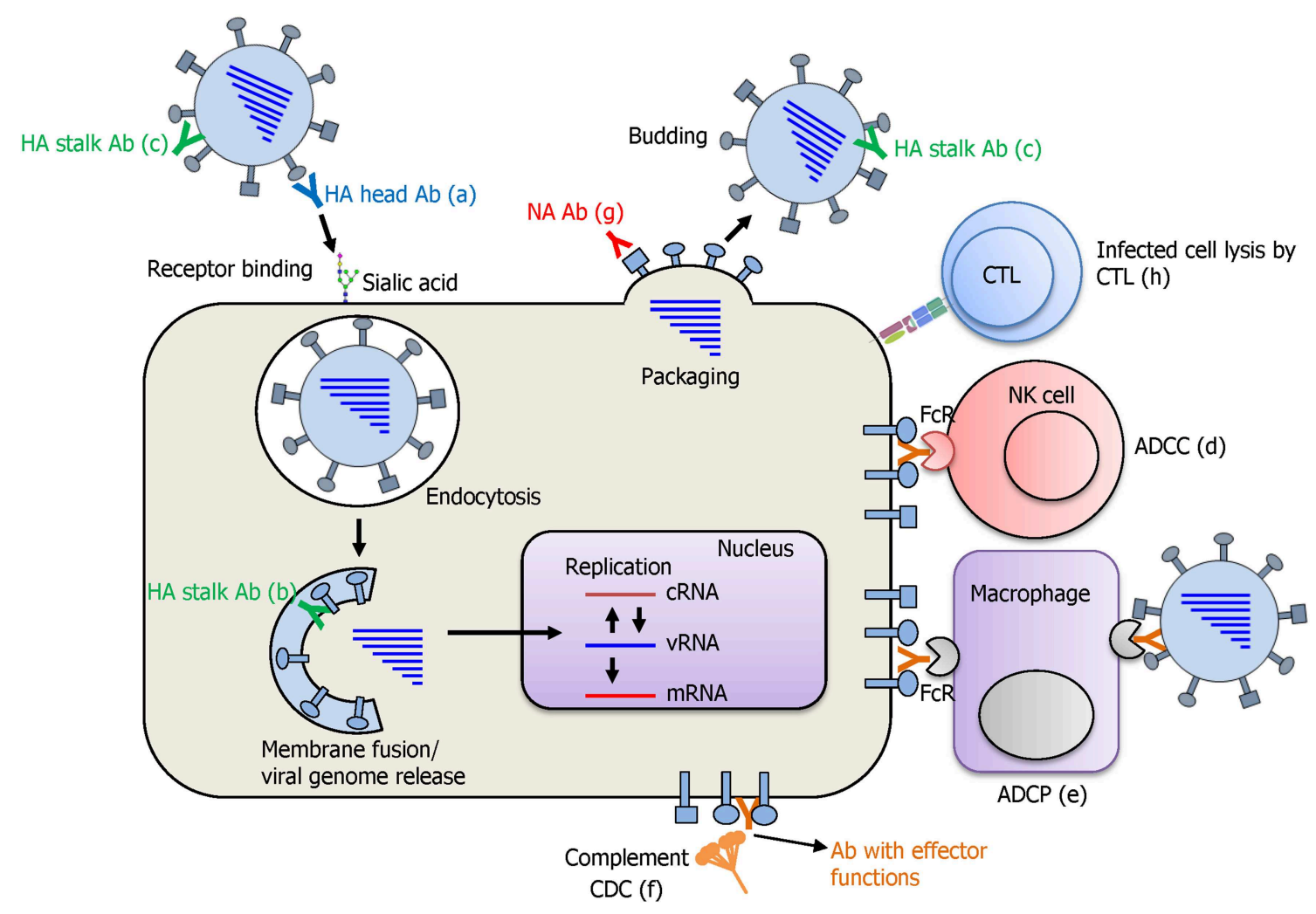

FIGURE 4 | Protection mode of action afforded by a UIV. Antibodies against the HA globular head domain inhibit viral attachment via HA-mediated receptor binding to the sialic acid on cellular receptors (a). HA stalk antibodies have multiple protective functions. As the virus enters the cell, pre-bound stalk antibodies prevent the fusion of viral and endosomal membranes and block the viral genome release into cytoplasm of the cell (b). Binding of stalk antibodies can also limit the access of cellular proteases to the cleavage site located in the stalk domain and inhibit the cleavage and subsequent conformational change of $\mathrm{HA}$ that is an essential step for acquiring viral infectivity (c). Different antibodies against HA stalk and also other viral proteins such as NA, M2, and NP are shown to mediate antibody-dependent effector functions such as antibody-dependent cellular cytotoxicity (ADCC), antibody-dependent cellular phagocytosis (ADCP), and complement-dependent cytotoxicity (CDC), leading to the lysis of the virus-infected cells by immune cells or complement system (d-f). NA antibodies inhibit receptor destroying activity of NA and prevent the budding of newly formed viral particles from the cells (g). Cytotoxic T lymphocytes (CTLs) recognize the viral peptide presented on MHC-I molecule and kill the virus infected cell by the secretion of cytotoxic granules and cytokines (h). 


\section{CURRENT STATUS OF M2e-BASED UIV APPROACHES}

IAVs have two major surface proteins, HA and NA, and one minor surface protein, the M2 ion channel. During the infection cycle, the M2 ion channel is responsible for acidification of the viral interior, facilitating virus uncoating, and unloading of viral ribonucleoproteins (RNPs) into the host cytoplasm (Pinto et al., 1992). The extracellular domain of M2 protein (M2e) consists of 24 amino acids, among which $9 \mathrm{~N}$-terminal amino acids are completely conserved among all IAVs (H1-H18) and minor mutations are observed in the distal portion (Deng et al., 2015a; Tsybalova et al., 2018). Therefore, M2e is considered as a promising target for eliciting broadly reactive antibodies. However, due to poor immunogenicity of the small M2e region, UIV approaches targeting M2e required carriers, vectors, and adjuvants to enhance immune responses (Deng et al., 2015a; Lee et al., 2015). One of the most efficient approaches is to make virus-like particles (VLPs) which display M2e on their surface. It has been shown that the hepatitis $\mathrm{B}$ virus core $(\mathrm{HBc})$ protein fused with M2e self-assembled into VLPs that resemble wild type virus particles, expressing M2e on the surface (Neirynck et al., 1999). Following this work, substantial efforts were made to improve the immunogenicity and protective efficacy of M2e$\mathrm{HBc}$ VLP vaccine constructs. Major strategies include the use of multiple copies of M2e by tandem repeats (Ravin et al., 2015; Sun et al., 2015; Tsybalova et al., 2015) and combination with adjuvants such as cholera toxin A1 (De Filette et al., 2006) or B subunit of Escherichia coli heat labile enterotoxin (LTB) (Zhang et al., 2009). The M2e-HBc VLP was further harnessed with $\mathrm{T}$ cell immunity by combining conserved $\mathrm{T}$ cell epitope from NP (Gao et al., 2013). The arginine-rich domain of $\mathrm{HBc}$ was shown to induce Th1-biased immune response of M2e$\mathrm{HBc}$ VLP by binding to RNA, leading to improved protection (Ibanez et al., 2013). Besides the HBc, M2e was fused with various coat or capsid proteins derived from other viruses including Malva mosaic virus (Leclerc et al., 2013), tobacco mosaic virus (Petukhova et al., 2013), Papaya mosaic virus (Denis et al., 2008), T7 bacteriophage (Hashemi et al., 2012), and RNA phage Q $\beta$ (Bessa et al., 2008). Moreover, the enveloped VLPs displayed M2e in a membrane-anchored manner by combining influenza matrix protein and transmembrane (TM) domain of HA fused into M2e. The Sf9 insect cells infected with baculoviral vectors expressing influenza M1 and M2e-TM of influenza HA produced influenza VLPs displaying much higher levels of M2e than the wild type virions (Kim et al., 2015, 2017). Other vaccine types, including DNA vaccines or recombinant protein vaccines expressing M2e with various carriers to enhance immune responses, have also been advanced (Deng et al., 2015a).

Many studies conducted on animals and humans have elucidated the mechanisms of cross-protection conferred by M2e-based vaccines. A common observation is that antibodies specific to M2e cannot directly neutralize the viruses but confer cross-protection by eliciting several mechanisms of antibodymediated and cell-mediated immune responses. The most wellcharacterized protection mechanisms include ADCC, ADCP, and CDC (Figure 4). Studies have shown that multiple types of immune cells including the natural killer (NK) cells, neutrophils, dendritic cells, or macrophages have the ability to sense the virusinfected cells by interaction with the $\mathrm{Fc}$ receptors $(\mathrm{FcR})$ and the Fc region of M2e antibodies. This results in killing (ADCC) or phagocytosis (ADCP) of the infected cells (Huber et al., 2001; Jegerlehner et al., 2004; Hashimoto et al., 2007; Guilliams et al., 2014). The complement is also known to bind to the Fc of $\mathrm{M} 2 \mathrm{e}$ antibodies and triggers the complement cascade, leading to formation of the membrane attack complex and target cell lysis (CDC) (Wang et al., 2008; Kim et al., 2018b). These studies together suggest that M2e-specific non-neutralizing antibodies play a crucial role in broad protection against IAVs through the clearance of the virus-infected cells. Besides non-neutralizing effector functions, it has also been shown that M2e-displaying recombinant bacteriophages induce HAI antibodies in a mouse model (Deng et al., 2015b). In addition, the $\mathrm{T}$ cell responses directed to M2e have been shown to contribute to crossprotection. Several studies have shown the presence of CD4 and CD8 T cell epitopes in M2e region in mice and humans (Jameson et al., 1998; Gianfrani et al., 2000; Mozdzanowska et al., 2003; Eliasson et al., 2008). In line with this, it has been demonstrated that CD4 T cell and CD8 T cell-mediated immunity are critical for cross-protection elicited by M2e-based UIVs including VLPs or recombinant peptide vaccines (Lee et al., 2014; Zhang et al., 2016; Arevalo et al., 2017; Pendzialek et al., 2017; Eliasson et al., 2018).

It remains a challenge to overcome the low protective efficacy of M2e-based vaccines, due to intrinsic low immunogenicity of the vaccine antigen and the low abundance of M2 proteins on influenza virions and infected cells. From the clinical and practical standpoints, multiple immunizations with a high dose of vaccine antigens combined with potent adjuvants may pose safety concerns, rendering M2e-based vaccine approaches inadequate as a stand-alone UIV. Consequently, M2e antigen was combined with other influenza viral antigens (mostly HA) or supplemented with strain-specific vaccines, resulting in improved potency, and broader cross-protection. For instance, several studies combined M2e with influenza HA head or stalk domain to elicit broadly protective immunity against heterologous influenza infections with various vaccine platforms including nanoparticles, recombinant proteins, and recombinant influenza viruses (Guo et al., 2017; Bernasconi et al., 2018; Deng et al., 2018; Tsybalova et al., 2018). Supplemented vaccination with $\mathrm{M} 2 \mathrm{e}$ was examined to overcome the strain-specific protection or poor immunogenicity of classical inactivated or split vaccines (Music et al., 2016; Song et al., 2016). Besides the approaches described above, a vast amount of research on M2e-based UIVs have accumulated in the last decade, which are described in specialized reviews (Deng et al., 2015a).

\section{HA STALK-BASED UIV APPROACHES \\ General Principles of HA Stalk-Based Approaches}

The HA stalk-based approach currently leads the mainstream of UIV development. Influenza HA is the primary target antigen of the currently licensed seasonal vaccine, and HAI antibodies serve as the "gold standard" when evaluating the protective 
efficacy of HA-based vaccines (Ohmit et al., 2011). However, HA-based vaccines provide only strain-specific protection to antigenically homologous viruses, necessitating annual update of the surface antigens of seasonal vaccines to match the circulating viral strains. HA comprises two distinct domains; globular head, and stalk domains. The head domain is highly variable and immunologically dominant and thus the majority of $\mathrm{HI}$ antibodies are directed to the head domain that harbors the RBS (Figure 5). In contrast, the HA stalk domain is relatively conserved among the viruses, and therefore eliciting antibodies specific to the stalk is considered as a key to developing a UIV. However, the stalk is generally regarded as immunologically subdominant, due to masking effect by bulky head domain and close proximity to the viral membrane (Krammer and Palese, 2013; Crowe, 2018; Krammer, 2019), which necessitates rational design of a HA antigen and novel vaccination strategies to increase stalk-reactive antibodies. The major protective function of HA stalk antibodies is to lock the HA trimer in a prefusion state. This prevents $\mathrm{pH}$-dependent conformational change of HA that triggers the membrane fusion and release of viral genome into cytoplasm of host cell (Ekiert et al., 2009). The membrane fusion inhibitory activity of the stalk antibodies may lead to neutralization of influenza viruses, although the neutralizing potency is weaker than head antibodies that directly prevent the receptor binding. Besides the neutralizing activity, stalk antibodies have multiple indirect mechanisms that contribute to broad protection, including antibody-dependent effector mechanisms (Jegaskanda et al., 2017b) and the inhibition of the NA enzymatic activity (Wohlbold et al., 2016; Chen et al., 2019). To overcome the low immunogenicity of HA stalk, genetic modifications were required for efficient exposure of stalk to the host immune system. Prime-boost vaccination with chimeric HAs or "headless" HAs were designed to boost stalk-reactive antibodies (Figure 5). Alternatively, hyperglycosylation in HA head resulted in the redirection of immune response from head to stalk (Krammer and Palese, 2015) (Figure 5). These approaches have paved the way to increase the breadth of protection against influenza viruses.

\section{Protection Mechanisms of HA Stalk-Based Vaccine}

A primary function of stalk-reactive antibodies is membrane fusion inhibition. Following the influenza virus entry into the cells via endocytosis, a $\mathrm{pH}$-dependent conformational change of HA proteins triggers the membrane fusion between the virus and endosome, leading to release of the viral genome into the cytoplasm. Binding of the antibody to the stalk interrupts the conformational change of $\mathrm{HA}$ and prevents subsequent membrane fusion. This leads to the trapping of the virus in the endosome, eventually aborting the infection (Ekiert et al., 2009; Sui et al., 2009). Moreover, binding of the stalk antibody blocks the access of proteases to the cleavage site located in stalk region and prevents protease-dependent cleavage of the HA precursor into HA1 and HA2 subunits, which is a prerequisite for the conformational change of HA (Ekiert et al., 2009; Brandenburg et al., 2013). These two overlapping functions of stalk-reactive antibodies result in inhibition of membrane fusion and direct neutralization of the virus. In addition to these mechanisms that operate at the early stage of infection, the stalk antibody may also bind to the newly expressed HA proteins on the cell surface, and interfere with the viral budding or release, at the later stage of infection (Tan et al., 2014).

In addition to direct neutralization, stalk antibodies have indirect mechanisms that involve diverse innate immune cells to clear the virus-infected cells from the host. The NK cells sense virus-infected cells via interaction between FcR and Fc portion of antibody bound to HA stalk expressed on the cell surface, and kill the infected cells by releasing cytotoxic granules and antiviral cytokines, via ADCC mechanism (DiLillo et al., 2014) (Figure 4). The FcR-Fc interaction is also required for ADCP, by which macrophages or neutrophils recognize and engulf antibodybound influenza viral particles or infected cells (Ana-Sosa-Batiz et al., 2016). In addition, stalk antibodies bound to virus-infected cells are also able to activate the complement system, leading to the lysis of virus-infected cells (CDC) (Terajima et al., 2011). Animal challenge models have demonstrated broad protection by passive immunization with HA stalk monoclonal antibodies (DiLillo et al., 2014, 2016). The stalk-reactive antibodies also inhibit NA enzymatic activity through steric hindrance, limiting NA access to the HA-bound sialic acid, thereby preventing viral egress (Wohlbold et al., 2016; Chen et al., 2019; Kosik et al., 2019). The failure to release newly assembled virions from the infected cells prevents the viruses from entering into multiple cycles of infection. Overall, the stalk antibodies confer a broad protection from influenza virus infection through multiple mechanisms affecting both HA and NA throughout the infection cycle of influenza virus.

\section{HA Stalk-Based Vaccine Constructs}

The first reported HA stalk-based UIV construct is the headless HA, a deletion mutant of HA lacking the globular head region (Graves et al., 1983; Sagawa et al., 1996; Steel et al., 2010) (Figure 5). While the initial strategies demonstrated broadly protective potentials in animal models, the removal of the head region often led to misfolding of the stalk immunogen, rendering the critical neutralizing epitopes ineffective. Subsequent studies were conducted to enhance the structural integrity of the stalk immunogens by rational designs to mimic the native trimeric conformation (Lu et al., 2014; Mallajosyula et al., 2014; Impagliazzo et al., 2015). Other studies designed and evaluated nanoparticle structures consisting of the stalk antigens for broad protection in mice and ferret models (Yassine et al., 2015; Corbett et al., 2019). The second approach to preferably induce stalkreactive antibodies is based on chimeric HA that consists of stalk domain derived from the major target strains such as $\mathrm{H} 1$, $\mathrm{H} 3$, or B viruses fused with head domain from irrelevant avian strains such as H5, H6, or H8 (Krammer and Palese, 2015) (Figure 5). Multiple immunization was required to increase the stalk antibodies sufficient to provide protection from viruses within the same HA group (Hai et al., 2012; Krammer et al., 2013, 2014). The chimeric HA approach involves a full-length functional HA protein and, therefore, it may be expressed in genetically engineered viruses of the wild type or live attenuated 


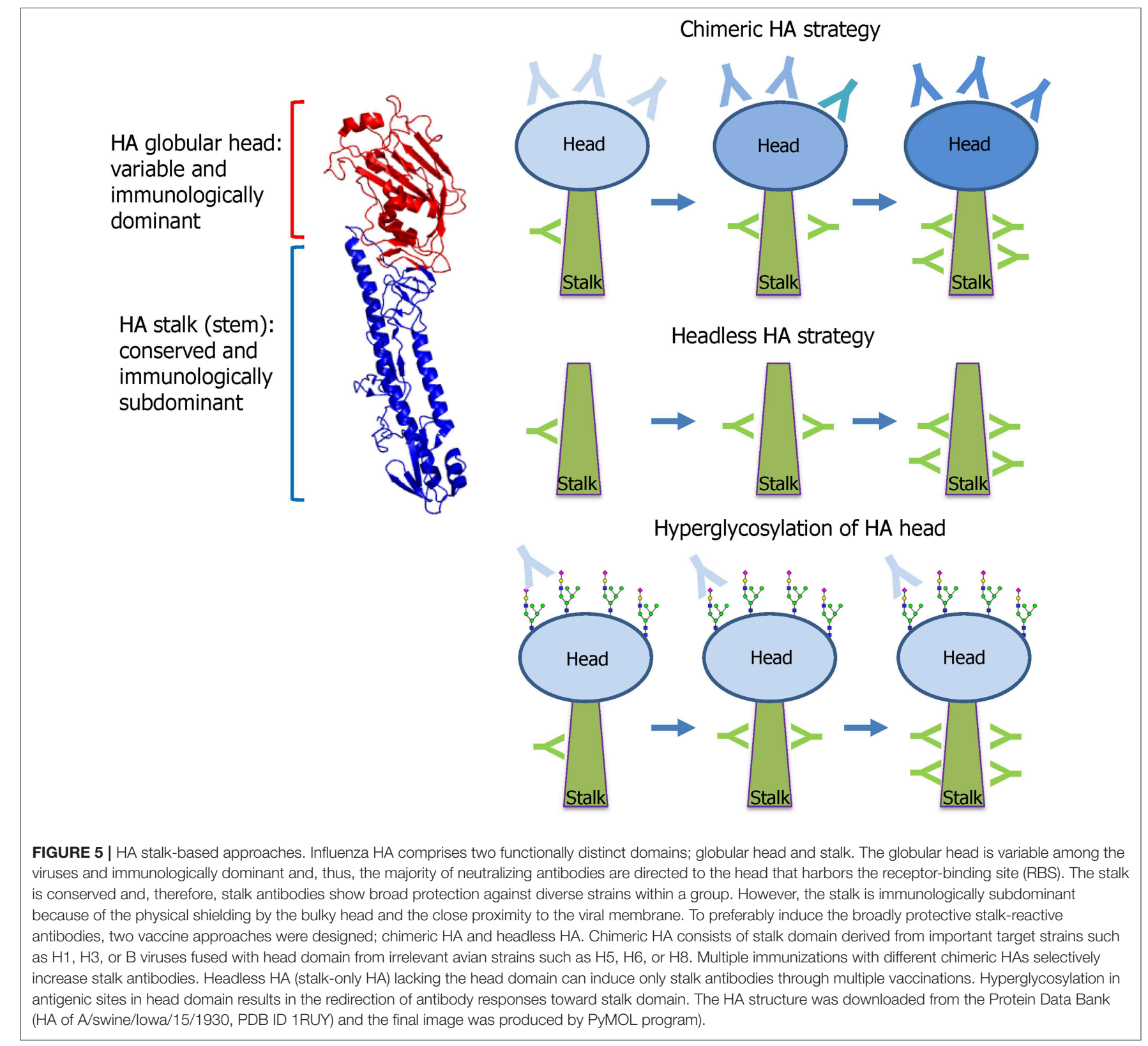

influenza viruses (Krammer et al., 2013; Isakova-Sivak et al., 2018). Third approach relies on hyperglycosylation in the HA head domain (Figure 5). The introduction of additional Nglycosylation sites into the immunodominant head domain shields the major antigenic sites in the head and redirects the host immune responses toward the immune-subdominant stalk. The hyperglycosylated HA antigens induced higher stalk antibodies and provided better protection than the wild type HA in a mouse model (Eggink et al., 2014). Similar approaches were tested for avian $\mathrm{H} 5 \mathrm{~N} 1$ vaccines, in which hyperglycosylated HA antigens were delivered in various vaccine formats such as DNA, recombinant protein, VLP, and adenoviral vector (Lin et al., 2012, 2014). A recent study has shown that glycan shielding of HA head resulted in immune focus on a conserved epitope occluded at the head interface, with Fc-dependent protection activity in mice (Bajic et al., 2019a). These results together suggest that hyperglycosylation in the HA head is a promising strategy to find novel target epitopes hiding in the head and stalk in HA.

\section{Current Issues in HA Stalk-Based UIVs Vaccine Efficacy}

As discussed above, the protective efficacy of HA-stalk based vaccines is relatively weak, and multiple boost immunizations are required for efficient protection (Krammer et al., 2013, 2014). In addition, the breadth of protection is within the same HA group rather than both the groups (Krammer et al., 2013). To complement the low efficacy, prime-boost approaches that entail sequential immunization by LAIV followed by inactivated virus 
containing chimeric HAs are being evaluated. As examined by a ferret challenge model, this approach provided potent cross protection (Nachbagauer et al., 2017). It was observed that there is a "disconnect" between stalk antibody titers in serum and the protection level (Nachbagauer et al., 2017). The results show that the broad protection observed in the ferret model was primarily mediated by multiple-level immune responses by LAIV and rather than the stalk antibodies (see section Live attenuated influenza vaccine as an alternative strategy below). This observation in preclinical model leads to the question of the relevance of HA stalk antibodies to cross-protection in humans. Studies with human infection model have led to a somewhat different interpretation on the protective role of the stalk antibodies, depending on the study design. A human challenge study showed that the naturally occurring stalk antibody titers were predictive of lowering viral shedding, but demonstrated poor correlation with the reduction of clinical symptoms upon the pandemic A/H1N1 challenge (Park et al., 2018). In contrast, a more recent study suggested the preexisting HA stalk antibodies as an independent correlate of protection against natural infection with the pandemic $\mathrm{A} / \mathrm{H} 1 \mathrm{~N} 1$ virus $(\mathrm{Ng}$ et al., 2019). Thus, further studies are required for a conclusive demonstration of the breadth and efficacy of cross-protection offered by HA stalk antibodies in human challenge models.

\section{Potential Vaccine Safety Issues}

Although the HA stalk based strategies have shown promising broad protection in animal models, potential safety issues have been raised (Crowe, 2018; Khurana, 2018). It is suggested that the stalk antibodies are responsible for antibody-dependent enhancement of viral infectivity in a swine model. In a study, pigs vaccinated with inactivated $\mathrm{H} 1 \mathrm{~N} 2$ vaccine developed more severe respiratory diseases upon heterologous $\mathrm{H} 1 \mathrm{~N} 1$ challenge as compared to the non-vaccinated control, which was ascribed to infectivity-enhancing effects of stalk antibodies (Khurana et al., 2013). Similarly, the HA subunit vaccine resulted in vaccineassociated enhanced respiratory disease (VAERD) in pigs after heterologous challenge (Gauger et al., 2011; Rajao et al., 2014). This effect cannot be generalized as the enhancement was noticed only in the adjuvanted antigen in a swine model, but not seen in similar studies with non-adjuvanted vaccines in a ferret model (Krammer et al., 2014). In addition, it has been recently shown that head-reactive, non-neutralizing monoclonal antibodies increase the stalk flexibility and membrane fusion kinetics, resulting in enhanced respiratory disease in a mouse model (Winarski et al., 2019). These results indicate that head-reactive antibodies may also induce antibody-dependent enhancement. However, similar observations in humans are debatable. For instance, humans immunized with 2008-2009 inactivated TIV exhibited an increase in illness following infection with 2009 H1N1 pandemic virus (Janjua et al., 2010; Skowronski et al., 2010) due to the presence of cross-reactive antibodies (Monsalvo et al., 2011). Similar fatal cases were observed during 1957 H2N2 pandemic, although the relation of HA stalk antibodies to these observations is not known. It is noteworthy that NAI antibodies could reduce VAERD caused by mismatched heterologous HA, suggesting that vaccines which target $\mathrm{HA}$ protein alone may be prone to VAERD and cross-protective NAI antibodies may counteract VAERD (Rajao et al., 2016). Although there is no report on VAERD associated with the headless or chimeric HA vaccines, careful monitoring is advised as these approaches rely heavily on stalk antibodies. The inclusion of NA antigens into HA stalk-based vaccine merits further evaluation. Another issue raised by a recent study is the auto-reactivity of stalk antibodies to human proteins, which is significantly higher than the head antibodies, as confirmed by multiple in vitro assays (Bajic et al., 2019b). Although biological implications of this observation have not been studied in vivo, it was speculated that vaccine strategies focused exclusively on the stalk, or any single conserved epitope may fail to induce adequate antibody titers due to negative selection of the auto-reactive $\mathrm{B}$ cell clones (Bajic et al., 2019b). However, clinical observations showed that, despite under potential negative selection, preexisting stalk antibodies conferred protection against the 2009 pandemic A/H1N1 infection in humans (Ng et al., 2019).

\section{Stalk Variability}

Although conserved among the influenza viruses, the HA stalk is not antigenically identical, showing sequence variability even within the same HA subtype. In line with this, a study demonstrated that H1 HA stalk could undergo mutations in vitro by immune pressure, although the variability was less than the head region (Anderson et al., 2017). On the other hand, another study show that while the stalk domain does evolve over time, this evolution is slow and, historically, is not directed to aid in evading neutralizing antibody responses (Kirkpatrick et al., 2018). Several studies have isolated mutant influenza viruses showing resistance to stalk antibodies (Ekiert et al., 2011; Friesen et al., 2014; Chai et al., 2016). Notably, all isolated resistant viruses were seen to harbor three different mutations (Gln387Lys, Asp391Tyr, and Asp391Gly) in stalk region. While Gln387Lys mutation completely abolished the binding of the antibody to stalk region, the other two mutations rarely affected the antibody binding but enhanced the fusion ability of HA, representing two independent resistance mechanisms of the virus to escape stalk-reactive antibodies (Chai et al., 2016). These reports together show that the stalk may undergo natural or directed antigenic changes, asking important considerations in the context of developing stalk-based UIVs. Especially, the occurrence of mutations that enhance the membrane fusion of HA in presence of stalk antibodies presents a potential concern to vaccine safety issues. It should, however, be noted that the stalk antibody escape mutants tend to lose a viral fitness and are highly attenuated in vivo (Henry Dunand et al., 2015; Chai et al., 2016), alleviating the safety concerns.

\section{Rational Design of Stalk}

It is well-recognized that the stalk is less immunogenic than head and that the stalk antibodies are less potent in virus neutralization than the head antibodies. Therefore, multiple immunizations (three or four times) with stalk-based vaccines are required for inducing a sufficiently protective level of antibody response. More importantly, most humans have a diverse history of exposure to influenza antigens, by natural 
infection, or vaccination. The established immune memory influences the subsequent immune response to a UIV, posing a great challenge to rendering qualitatively uniform and protective immune responses in humans. As discussed earlier, the HA stalk-based vaccines elicit broad-spectrum protection within the same HA group, but usually fail to provide protection to strains belonging to different HA group (Krammer et al., 2013; Margine et al., 2013). These results apparently dissent from the finding that some of the stalk monoclonal antibodies isolated from humans recognize all IAV subtypes, neutralizing both group 1 and group 2 viruses, presenting a promising prospect of developing pan-influenza A therapeutic solution (Corti et al., 2011). Isolation of rare antibodies with extremely broad neutralization potency from humans with prior vaccinations or infections (Corti et al., 2011) indicates that our immune system is able to find the cryptic and conserved epitopes and generate specific antibodies to the regions. However, inducing such antibodies to a protective level by vaccination remains a big challenge. Some recent reports encourage other options such as the activation of the conserved "cryptic" epitopes via antigen processing mechanisms (Lee et al., 2018b) or deliberately downregulating surface antigens (Yang et al., 2013). Moreover, Fcengineering technologies developed to enhance the therapeutic efficacy of antibodies may be harnessed to modulate FcR-Fc mediated effector functions (DiLillo et al., 2014) to achieve broad protection. A comprehensive understanding of immune response to broadly neutralizing epitopes and structure-based antigen design is required for the rational design of a pan-influenza $\mathrm{A}$ vaccine covering both group 1 and group 2 IAVs, as a consensus criterion of UIV (Table 1).

\section{CONSERVED TARGETS IN HA OTHER THAN STALK}

The inability to induce a complete protection by HA stalkbased approach led to a search for alternative targets for UIVs. Human monoclonal antibody CH65, mimicking the interaction with sialic acid, was shown to bind to the RBS in HA and neutralize multiple H1N1 influenza strains (Whittle et al., 2011). A caveat is that this antibody demonstrated stringent structural requirements for neutralization and mutation at the binding region led to generation of escape mutants. A panel of headreactive monoclonal antibodies was also isolated and shown to recognize conserved region in the RBS and neutralize multiple influenza viruses (Krause et al., 2011, 2012; Ekiert et al., 2012; Benjamin et al., 2014).

The HA head domain was also reported to contain conserved epitopes outside the RBS. Different broadly neutralizing antibodies recognized the conserved regions located in HA head domain and neutralized multiple influenza viruses without detectable HI activity (Iba et al., 2014; Raymond et al., 2018). Generally, neutralization breadth of head antibodies was considerably variable to each other, ranging from pan-subtype (covering the same subtype) to pan-type (covering both group 1 and 2) coverage, indicating the presence of variably conserved regions. Additionally, a novel class of cross-reactive antibodies was discovered in humans vaccinated with seasonal TIV (Lee et al., 2016). These antibodies were shown to bind to a highly conserved region located on the HA RBS that was occluded in the HA trimer, conferring protective immunity against $\mathrm{H} 1 \mathrm{~N} 1$ and $\mathrm{H} 3 \mathrm{~N} 2$ strains in vivo, without neutralizing activity in vitro. Furthermore, a novel class of antibodies targeting vestigial esterase (VE) domain in HA has been characterized. The VE domain consists of two non-continuous sequences in HA head domain, which together forms a structurally distinct subdomain from the RBS and HA stalk domain (Zheng et al., 2018). The VE domain of the HEF protein of ICV is responsible for cleaving the host receptor to facilitate viral release, whereas in IAVs and IBVs the same receptor cleaving function is provided by a separate NA. The VE domains are found in both IAVs and IBVs, although their functions are not well-defined. The VE domains are highly conserved within a subtype of IAV but are variable among different subtypes (Ha et al., 2002). Monoclonal antibodies to the VE domain of $\mathrm{H} 5 \mathrm{~N} 1$ virus demonstrated broad neutralization against multiple clades of $\mathrm{H} 5 \mathrm{~N} 1$ subtype by preventing viral entry into cells (Oh et al., 2010). To date, different monoclonal antibodies have been isolated and they bind to different epitopes in the $\mathrm{VE}$ domain of $\mathrm{H} 5 \mathrm{~N} 1$ viruses, suggesting the presence of multiple neutralization epitopes in the VE domain (Paul et al., 2017). The VE-binding antibodies are reported to mediate ADCC for in vivo protection via FcR-Fc interaction (Wang et al., 2017). Besides H5N1, several monoclonal antibodies neutralizing $\mathrm{H} 3$ or H7 of IAVs or IBVs have also been recently characterized (Tan et al., 2016; Chai et al., 2017; Bangaru et al., 2018). Taken together, possibility remains to identify conserved neutralizing epitopes in the head domain in HA, in addition to extensively characterized HA stalk. Activation of these epitopes via antigen processing machineries (Lee et al., 2018b) may offer an option for enhancing the potency of cross-protection.

Despite the presence of conserved epitopes, the head domain is not a feasible vaccine antigen because of the immunodominance of the surrounding variable regions in the head that compete and prevent effective induction of antibodies toward the conserved regions. Therefore, several strategies were designed to enhance the breadth of protection by HAbased vaccines. The centralized HA was reconstructed such that whole HA contained consensus amino acids derived from diverse strains within a subtype (Weaver et al., 2011). This engineered $\mathrm{HA}$ antigen induced stronger immune response and provided better protection against heterologous influenza viruses, as compared to natural wild type HA antigen. Another approach, conceptually similar to the centralized HA, is based on a computationally optimized broadly reactive antigen (COBRA), in which the HA was designed to carry consensus sequences. The COBRA strategy was tested against $\mathrm{H} 1 \mathrm{~N} 1, \mathrm{H} 3 \mathrm{~N} 2$, and $\mathrm{H} 5 \mathrm{~N} 1$ influenza viruses, and demonstrated broad protection within a subtype (Giles and Ross, 2011; Crevar et al., 2015; Carter et al., 2016). A third strategy is the use of ancestral sequences as vaccine antigens to widen the window of cross-protection against diversified lineages or clades. Through phylogenetic tree analysis, putative ancestral HA and NA sequences have been determined and used as vaccine antigens, showing broadened cross-protection against multiple clades of $\mathrm{H} 5 \mathrm{~N} 1$ viruses in 
animal models (Ducatez et al., 2011, 2013). Collectively, the UIV candidates using HA head or full-length antigen are based on reconstructed HA containing consensus sequences. Although the protection breadth of those strategies appears to be restricted to a subtype or a specific clade, similar concepts may be applied to other antigens such as HA stalk or NA to substantially improve the protection breadth.

\section{NA AS A NOVEL TARGET FOR A UIV Multiple Function of NA in Infection Cycle}

$\mathrm{NA}$ is a tetrameric type II transmembrane glycoprotein and the second major surface protein of influenza viruses. The role of NA in influenza infection cycle is classically known as an expedited release of virus particle from infected cells by cleaving off the sialic acid residue present in host cell membrane, thus enabling multiple rounds of infection by the newly generated viral progeny. In addition to the canonical role that operates at later stage of infection, other functions of NA relevant to the infection cycle are being recognized. For instance, the sialidase activity of NA is critical for viral entry into a host cell at early stage of infection. At the entry site in the mucus, influenza virus meets mucosal defense proteins such as mucins that are highly glycosylated and capture viral HA. NA is able to release the captured viral particles via sialidase activity, allowing them to reach the host cells successfully (Cohen et al., 2013; Yang et al., 2014). Furthermore, with the same sialidase activity, NA facilitates HA-dependent membrane fusion and enhances the viral infectivity by removing the sialic acid residues from the virion-expressed HAs (Su et al., 2010). Additionally, NA cooperates with $\mathrm{HA}$ to enable crawling and gliding motions of influenza virus on cell surface to enhance viral entry into a cell (Sakai et al., 2017). More interestingly, some of the H3N2 viruses use their NA for receptor binding instead of HA, suggesting a novel role of NA other than receptor-destroying activity (Lin et al., 2010; Mogling et al., 2017). These observations show that NA performs multiple functions in the entire infection cycle, suggesting that NA antibodies may represent an important means of protection against influenza viruses.

\section{NA Antibodies as Important Correlate of Protection}

The 1968 H3N2 pandemic gave us important lessons pertaining to NA-mediated protection. The antigenic drift of NA is independent of HA; the pandemic involved a shift in HA, but NA remained close to the previous influenza A/H2N2 viruses (Schulman and Kilbourne, 1969). Notably, it has been shown that individuals with higher N2 antibody titers are less likely to be infected with the $\mathrm{H} 3 \mathrm{~N} 2$ pandemic, depicting the contribution of NA antibodies to broad protection (Schulman, 1969; Murphy et al., 1972; Monto and Kendal, 1973). However, NA has been largely ignored in the formulation of influenza vaccines due to the general beliefs that NA antibodies do not inhibit viral entry and that NA is less abundant than HA on a virion. Furthermore, the lack of a convenient assay to measure functional NA antibodies has rendered the NA forgotten antigens in influenza vaccines for decades (Eichelberger and Monto, 2019). Most of the current vaccine approaches focus on the induction of HA antibodies, both in trivalent/quadrivalent seasonal influenza vaccines and in the recent UIV candidates. However, it has been increasingly acknowledged that NA antibodies are important and independent correlates of protection and that NA immunity should be considered when evaluating vaccine potency. Clinical studies have shown a correlation between vaccination-induced or preexisting NAI antibody levels and decreased frequency of influenza infection and illness (Couch et al., 2013; Monto et al., 2015; Park et al., 2018). Further, a human challenge model depicted that NAI titers correlated more significantly with protection and disease severity than HAI titers (Memoli et al., 2016), or even HA stalk antibodies (Park et al., 2018). The observations in the human challenge models suggest that NA should be given full consideration as a vaccine antigen for better protection.

Several animal studies have identified NAI monoclonal antibodies that show protective effects against heterologous influenza infection. The breadth of NAI antibodies varied from subtype-specific to pan-influenza, depending on the conserved epitopes (Doyle et al., 2013a,b; Wan et al., 2013). Recently, it was reported that influenza infection in humans induces a variety of broadly reactive antibodies directed to the NA (Chen et al., 2018). In this study, it was shown that among the total influenza-specific antibodies induced by infection, the NA-reactive antibodies accounted for $23 \%$ and HA-reactive antibodies $35 \%$. By contrast, the subunit or split vaccine resulted in antibody response directed predominantly to HA (87\%), with only $1 \%$ for NA. The poor ability of the seasonal vaccine to induce NA antibodies was apparently due to insufficient content or structural integrity of NA antigen used in current vaccine formulation. This research suggests that correctly folded and immunologically relevant NA antigen is capable of inducing broadly protective antibody responses.

\section{NA-Based Vaccine as Low-Hanging Fruit for a UIV?}

Although the importance of NA-immunity in protection against homologous and heterologous influenza infections is clearly established, only a few literatures have demonstrated the crossprotection of NA-only vaccine constructs. One recent study in a mouse model has reported that computationally engineered recombinant NA proteins containing consensus sequences show broad protection within the H1N1 subtype (Job et al., 2018). Some other studies reported that VLPs expressing NA provided cross-protection against heterologous challenge in mice and ferrets (Easterbrook et al., 2012; Walz et al., 2018; Kim et al., 2019), and recombinant NA in a mouse model (Liu et al., 2015; Wohlbold et al., 2015). However, co-administration of H7 HA and N3 NA in modified vaccinia virus Ankara (MVA) vectors did not demonstrate enhanced protection efficacy as compared to the efficacy of MVA-HA or MVA-NA vaccine alone (Meseda et al., 2018). A predominant immune response in favor of HA over NA, when presented in an influenza virion, is already welldocumented (Johansson et al., 1987), and the dissociation of HA and NA eliminates this antigenic competition (Johansson 
and Kilbourne, 1993, 1996). These observations together suggest that NA-specific immunity may be dwarfed by competition with highly immunogenic HA in the final vaccine formulation. It could be argued that if the controlled ratio of $\mathrm{HA}$ and NA (dwarfing NA) is the strategy adopted by successful virus infection to minimize the host immune surveillance, then a deliberate perturbation of their ratio (increasing NA) in the vaccine formulation may be a promising strategy for effective protection. It was shown that the ratio of HA/NA could vary widely (up to 50 fold) without affecting viral fitness by a single mutation in the viral promoter (Lee and Seong, 1998). It remains to be seen if such a reverse-genetic approach could be harnessed to enhance the potency of NA-based vaccines.

Currently, we have very limited knowledge about anti-NA immunity. To develop a broadly protective vaccine based on NA, there are several critical questions that need to be answered. Firstly, although the NAI antibodies have been determined as an independent correlate of protection in humans (Couch et al., 2013; Monto et al., 2015), this needs to be further validated by the NA-only vaccine constructs in animal and human models. Secondly, very little is known about the breadth of NA immunity. The literature discussed earlier has consistently demonstrated a subtype-specific protection (e.g., within N1 or N2) of NA-based vaccines in animal models. Considering the repertoire of influenza viruses infecting humans and animals (including $\mathrm{N} 1, \mathrm{~N} 2, \mathrm{~N} 3, \mathrm{~N} 7$, and $\mathrm{N} 9$ encompassing both NA group 1 and 2) (Figure 1), a successful NA-based vaccine should be designed to elicit broad protection covering both NA groups. Hence, the determination of conserved regions or epitopes hidden in NA is urgently needed. Thirdly, the mechanisms by which NA antibodies contribute to protection are not completely understood. Many NAI antibodies inhibit its enzymatic activity and thus prevent the release of newly formed viral particles. However, the extent to which NAI antibody titers may be considered protective has not been determined yet. Evaluation of cross-protection against mismatched or heterologous strains may be even more complicated. While ADCC was shown to be involved in protection by nonneutralizing NA antibodies (Jegaskanda et al., 2014, 2017a; Wohlbold et al., 2017), other protective mechanisms are yet to be further elucidated. Further isolation and characterization of broadly protective NA antibodies is required for better design of NA-based vaccines. Comprehensive reviews on NA-based immunity and the perspectives on current knowledge gaps to be addressed may be found in specialized reviews (Wohlbold and Krammer, 2014; Krammer et al., 2018a).

\section{UIV AGAINST INFLUENZA B VIRUSES}

Besides IAVs, $\sim 25 \%$ of all human influenza virus infections in each epidemic season is caused by IBVs that are classified into two distinct lineages, Victoria-like and Yamagata-like lineages (Ambrose and Levin, 2012). The current seasonal influenza vaccine is prepared in a trivalent or quadrivalent formulation, depending on the inclusion of one or two lineages of IBV antigens. Although priority is given to IAVs owing to a greater impact, IBVs may be more vulnerable targets against which to develop a UIV (Table 1) because of their low antigenic diversity and lack of animal reservoir (Figure 1) (Tan et al., 2018). Indirect evidence is being accumulated by the isolation of cross-protective antibodies against IBVs. Several broadly protective antibodies binding to head or stalk domain of influenza B HA have been isolated in humans. Overall, these monoclonal antibodies show lineage-specific neutralizing activity in vitro. Further, in vivo protection against both lineages was also demonstrated in mice by passive transfer, through non-neutralizing antibodydependent effector functions (Shen et al., 2017; Hirano et al., 2018; Vigil et al., 2018; Asthagiri Arunkumar et al., 2019; Liu et al., 2019b). Notably, some of B HA stalk antibodies demonstrated extremely broad binding ability (Hirano et al., 2018) or protection against both IAVs and IBVs (Dreyfus et al., 2012). Influenza B NA-reactive broadly neutralizing antibodies were also isolated in animals and humans. Seasonal QIV induced NA antibodies with broad and potent antiviral activity against both lineages in humans (Piepenbrink et al., 2019). Additionally, murine NA antibodies also showed broad protection against both lineages of IBV (Wohlbold et al., 2017).

In line with these observations, chimeric HA strategy has also been tested for a UIV against IBVs. Chimeric HAs consisting of HA head domain from IAV and stalk domain from IBV, delivered as a DNA vaccine (prime), followed by two boosting immunizations with protein vaccines into mice, provided broad protection against both the lineages as well as an ancestral strain of IBV (Ermler et al., 2017). Mosaic HA is an advanced version, in which major antigenic sites of type B HA head domain were replaced by those of type A HA head so that antibodies directed to conserved regions both in the head and stalk domains of type B HA could be induced (Sun et al., 2019). The mosaic B HA provided broad protection against both lineages of IBV, through non-neutralizing ADCC-mediating antibody responses. There are only a few studies reporting B NA-based vaccine offering cross-lineage protection. A study showed that mice immunized with recombinant B NA protein of B/Yamagata/16/88 were protected from homologous Yamagatalike and Victoria-like lineages (Wohlbold et al., 2015). Another study demonstrated that a B NA-based vaccine inhibited the transmission of both homologous and heterologous IBVs in Guinea pig model (McMahon et al., 2019). As compared to IAVs, very little effort has been made so far to develop a UIV against IBVs. However, considering the limited diversity and variability (Figure 1) compared to IAVs, further identifications of broadly protective $\mathrm{B}$ cell and $\mathrm{T}$ cell epitopes would make it possible to develop a pan-influenza B vaccine in the near future (Tan et al., 2018).

\section{T CELL IMMUNITY AS AN ESSENTIAL FACTOR FOR TRULY UNIVERSAL INFLUENZA PROTECTION}

A vast majority of current efforts to develop a UIV are focused on inducing antibody response toward surface glycoproteins, M2e, HA, and NA. However, T cell immunity has been acknowledged 
as a potential immune correlate of broad protection against influenza infections (Sridhar, 2016; Clemens et al., 2018). T cell immunity may not provide sterilizing or neutralizing immunity against influenza viruses but improves the standard of care by reducing the disease severity and duration of infection, facilitating recovery from illness (Sridhar, 2016). It, therefore, seems that multiple immune arms including both antibodies and $\mathrm{T}$ cell immunity are critical to provide a truly universal protection against highly variable influenza viruses. The influenza-specific $\mathrm{T}$ cell immunity is known to be highly cross-reactive by recognition of conserved peptides between different subtypes of IAV (Assarsson et al., 2008; Kreijtz et al., 2008; Lee et al., 2008; van de Sandt et al., 2014). Extensive studies have proven the protective role of vaccination or infection-induced cross-reactive CD8+ T cells in various animal models (Kreijtz et al., 2007, 2009; Bodewes et al., 2011; Hillaire et al., 2011). Additionally, in humans, CD8 + T cells offered cross-protection across seasonal, pandemic, avian IAVs, and both lineages of IBVs (Gras et al., 2010; Hayward et al., 2015; van de Sandt et al., 2015; Wang et al., $2018 b)$. The majority of cross-reactive $\mathrm{T}$ cell epitopes of IAVs are derived from internal proteins; among $>70 \mathrm{~T}$ cell epitopes identified between $\mathrm{H} 5 \mathrm{~N} 1$ and $\mathrm{H} 3 \mathrm{~N} 2$ viruses, only one derived from HA and other from internal proteins (Lee et al., 2008). This is not surprising given that the conservation rate of internal proteins is $>90 \%$, whereas that of surface HA and NA is only $40-$ $70 \%$ among IAVs (Lee et al., 2008), which shows that inducing $\mathrm{T}$ cell immunity directed to internal proteins of influenza virus may provide a basis of developing T cell-based UIVs.

Despite poor sequence homology between the HAs of IAVs and IBVs, HA stalk harbors not only extremely broad B cell epitopes but also $\mathrm{T}$ cell epitopes encompassing both types of influenza viruses. The fusion peptide in HA stalk contains a cross-reactive CD4+ T cell epitope conserved in both IAVs and IBVs, although its protective role has not been examined in vivo (Babon et al., 2012). A number of CD4+ and CD8+ T cell epitopes are highly conserved in internal proteins (Terajima et al., 2013). A recent study has discovered a universal human CD8+ T cell epitope in PB1 (NMLSTVLGV PB1413-412) that is identical across IAVs, IBVs, and ICVs (Koutsakos et al., 2019). The preexisting memory $\mathrm{PB}_{413-412}+\mathrm{CD} 8+\mathrm{T}$ cells were detected in the blood and lung tissues of healthy donors and clonally expanded upon infection with IAV or IBV. This report not only showed the existence of heterotypic memory CD8+ T cells in humans that could be induced by exposure to influenza viruses, but also presents the prospect of designing a T cell-based UIV. However, these cross-reactive $\mathrm{T}$ cells were not induced in HHD-A2 mouse model despite multiple influenza infections or vaccinations and the protective role of the $\mathrm{T}$ cells could not be assessed in the study. Nonetheless, the existence of a number of cross-reactive T cell epitopes between IAVs and IBVs provides an avenue to address to a UIV.

Several T cell-based vaccine candidates are in different stages of clinical development, the major underlying strategy of which is to deliver multiple $\mathrm{T}$ cell epitopes derived from different viral antigens including internal as well as surface antigens (Sridhar, 2016). Delivery platforms include replicating or nonreplicating viral vectors derived from vaccinia or adenovirus, recombinant VLPs, recombinant protein or peptide vaccines, and DNA vaccines (Sridhar, 2016; Clemens et al., 2018). Modified vaccinia Ankara (MVA) vector encoding NP and M1 was shown to induce robust $\mathrm{T}$ cell responses and provide cross-protection against multiple subtypes in animals and humans (Antrobus et al., 2012; Powell et al., 2013; Hessel et al., 2014; Folegatti et al., 2019). The baculovirus VLPs carrying influenza HA/NA and $\mathrm{M} 1$ offered cross-protection where $\mathrm{T}$ cells played a significant role in protection in mice (Hemann et al., 2013; Keshavarz et al., 2019). Synthetic peptides or fusion proteins harboring multiple conserved $\mathrm{T}$ cell epitopes have also been evaluated for immunogenicity and protective efficacy in animal models (Adar et al., 2009; Rosendahl Huber et al., 2015). While the vaccine approaches described above deliver exogenous antigens and induce CD4+ T cells as well as CD8+ T cells by crosspresentation, DNA vaccines are designed to predominantly activate cytotoxic CD8 $+\mathrm{T}$ cells to recognize endogenously expressed antigens presented on MHC class I molecules. In fact, the first report on DNA vaccines was targeted to influenza virus (Cohen, 1993; Ulmer et al., 1993), but initial success in a mouse model did not well-translate into higher animal models due to poor performance (Porter and Raviprakash, 2017). To date, much progress has been made to improve the efficacy of DNA vaccine against influenza virus, encompassing rational design of antigens and expression vectors and the development of novel adjuvants and delivery methods (Lee et al., 2018a). Candidate universal DNA vaccines encoding NP, matrix proteins, or PB1 were shown to decrease viral load and cross-protect against heterologous challenges in diverse animal models including mice, pigs, ferrets, and macaques (Ulmer et al., 1993; Tompkins et al., 2007; Price et al., 2009; Bragstad et al., 2013; Wang et al., 2015; Koday et al., 2017). Further studies are required for to refine DNA vaccine approaches as a stand-alone UIV. Recent studies have indicated that DNA vaccines may serve an attractive component of prime-boost strategy, considering it as a very effective means to priming immune system when preexisting immunity is low (Ledgerwood et al., 2013; DeZure et al., 2017). Despite the potential for broad protection, the safety issues need to be monitored closely, especially because of the documented rise in pathological consequences associated with CTL responses (Peiris et al., 2010; Duan and Thomas, 2016).

\section{LIVE ATTENUATED INFLUENZA VACCINE AS AN ALTERNATIVE STRATEGY}

\section{Cross-Protective Immunogenicity of LAIV}

LAIV has been approved for clinical use in humans since 2003 and is proven effective in preventing influenza infections (Mohn et al., 2018). The protection of LAIV is superior to IIVs due to multifaceted immune arms including antibody responses and cell-mediated responses that operate systemically and locally (Jang and Seong, 2013a,b; Sridhar et al., 2015). Further, displaying a whole set of viral antigens in a native conformation into the host immune system presents a definite advantage of LAIV to generate better protective immunity than the other strategies relying on a limited set of antigens. As discussed above, $\mathrm{T}$ cell 
immunity directed to the conserved viral epitopes constitutes the cornerstone of cross-protection. A large number of researches have shown that $\mathrm{T}$ cell responses induced by LAIV are critical for broad protection against heterologous and heterosubtypic influenza infections in animal models (Cheng et al., 2013; Jang and Seong, 2013a; Rekstin et al., 2017). In young children, only LAIVs were shown to induce durable and potent $\mathrm{T}$ cell responses, while developing similar levels of antibody response as compared to IIVs (Belshe et al., 2000; Hoft et al., 2011; Mohn et al., 2015, 2017). Despite well-documented cross-protection, LAIV has received little attention to develop a UIV. This may be attributed to the general belief that LAIV is not effective at inducing broadly neutralizing antibodies against conserved domains in surface antigens (e.g., M2e or HA stalk). However, close attention is recently being given to LAIV as an alternative platform as a potent and cross-protective vehicle than previously thought, through inducing multifaceted immune correlates including $\mathrm{T}$ cell response and antibody-mediated effector functions (Jang and Seong, 2013a, 2014).

\section{UIV Approaches Using LAIV}

In the UIV approaches reported so far, LAIV was used either as a component in prime-boost regimens with other different vaccine formats such as IIV, DNA vaccine, or recombinant protein vaccine. Alternatively, LAIVs were also studies as a standalone vaccine given in single or multiple doses. A reassortant LAIV expressing a chimeric HA was constructed under the genetic background of Russian strain (A/Leningrad/134/17/57 cold-adapted virus) and used as a boosting vaccine in a ferret model (Nachbagauer et al., 2017). Notably, the LAIV-IIV regimen showed greater protective efficacy against the pandemic $\mathrm{H} 1 \mathrm{~N} 1$ challenge than the IIV-IIV regimen in terms of viral loads in the respiratory tissues, despite 32 -fold lower stalk antibody titers in serum. Several factors were presumed to account for this disconnect between stalk antibody titers and protection efficacy, including anti-NA immunity, mucosal IgA antibodies, cellmediated immunity, and non-specific innate immune responses offered by the LAIV. Similar results were obtained when using a different LAIV strain (A/Ann Arbor/6/60 cold-adapted strain) (Nachbagauer et al., 2018). In a subsequent study performed by the same group, chimeric HA-containing the LAIV-LAIV (A/Leningrad/134/17/57 cold-adapted strain) vaccine regimen was compared with the LAIV-IIV combination in terms of protection efficacy in a ferret model, in which the LAIV-LAIV vaccine regimen conferred superior protection against pandemic H1N1 and H6N1 challenges than the LAIV-IIV (Liu et al., 2019a). Another group tested a vaccination regimen comprising only LAIV (A/Leningrad/134/17/57 cold-adapted strain) as primeboost vaccination in a mouse model (Isakova-Sivak et al., 2018). To enhance the breadth of protection, an internal gene of cold-adapted virus was replaced with the wild type. This study compared the immunogenicity and cross-protection between chimeric HA-containing LAIVs and natural HA-containing LAIVs. The chimeric HA-containing LAIVs induced higher HA stalk antibody titers and showed better cross-protection against heterologous infection with various group 1 IAVs. Thus, a cooperative role of cell-mediated immunity and HA stalk antibodies was suggested, although their individual contribution to protection were not assessed directly. It would be interesting to investigate if the cross-protection could be extended to group 2 influenza viruses such as $\mathrm{H} 3$ or $\mathrm{H} 7$ strains.

Besides the Leningrad and Ann Arbor strains, an independent cold-adapted vaccine strain (X-31ca) that was previously used for trivalent seasonal vaccine (Jang et al., 2014), H5N1 pre-pandemic vaccine (Jang et al., 2013c), and 2009 pdmH1N1 vaccine (Jang et al., 2012, 2013a), was recently tested as a UIV in a mouse model (Jang et al., 2018). Mice vaccinated with single or two doses of X31 ca LAIVs were completely protected against lethal challenge of heterosubtypic strains encompassing both HA group 1 and 2 IAVs. Interestingly, boosting with heterosubtypic LAIVs carrying different HA and NA surface antigens showed more potent cross-protection than homologous boosting. $\mathrm{T}$ cell immunity and NK cell-mediated ADCC activity was demonstrated to contribute significantly to the observed cross-protection. As the first report of pan-influenza A protection covering both HA groups, these results merit further studies in a ferret model for clinical relevance. Hence, the LAIVs appear to be a powerful tool to develop a UIV that confers broad and potent cross-protection as a stand-alone vaccine or in combination with other strategies.

\section{Future Prospects of LAIV-Based UIVs}

While the LAIV presents a remarkable prospect for a broadly protective influenza vaccine, several important issues need to be addressed for it to serve as a reliable vaccine modality. The protection efficacy of a LAIV substantially differs with age. The estimated protection efficacy of a LAIV is $80 \%$ in young children and only $40 \%$ in adults, to the matched strains (Jefferson et al., 2008, 2010). As for $\mathrm{T}$ cell immune responses, clinical studies indicate that LAIVs induce better T cell response than IIVs in both children and adults (He et al., 2006; Subbramanian et al., 2010; Hoft et al., 2011). However, clinical studies have reported that LAIVs are not effective at inducing $\mathrm{T}$ cell responses in adults and the elderly, perhaps due to preexisting "vector" immunity, which limits the replication of LAIVs (He et al., 2006; Forrest et al., 2008; Hoft et al., 2011). Considering that both humoral and cell-mediated immunity contribute to broad protection, it will be important to elucidate how preexisting immunity or immunologic imprinting affects $\mathrm{B}$ cell and $\mathrm{T}$ cell immune response induced by LAIVs in humans (Gostic et al., 2016; Henry et al., 2018). For this purpose, animal models mimicking preexisting immunity and controlled human challenge studies will be needed. Considering that LAIVs mimic natural infection, a fundamental question remains to be answered: if infection (or vaccination with LAIV) is effective for conferring protection, why are humans vulnerable to repeated infections with homologous or heterologous strains? At the population level, currently used cold-adapted LAIVs provide a relatively low protection rates ( $\sim 40 \%$ in adults) even against matched strains (Jefferson et al., 2010). However, little is known whether individuals who successfully acquired protective immunity by a cold-adapted LAIV were protected against other heterologous strain(s) in the next epidemic. This may be directly addressed by a wellcontrolled longitudinal cohort study using human challenge models. Some studies showed that LAIVs were able to generate 
cross-reactive $\mathrm{T}$ cell responses in children for up to 1 year after vaccination, as a basis of long-term cross-protection in humans (Mohn et al., 2015, 2017).

Most of the LAIV-based approaches are based on coldadapted attenuated strains (Nachbagauer et al., 2017, 2018; Jang et al., 2018; Liu et al., 2019a). These strains acquire multiple attenuation mutations in the internal genes during the coldadaptation process, which contribute to genetic stability to overall attenuation (Jang et al., 2016). A common concern for live vaccines is safety issues, especially those associated with potential reversion of attenuating mutation(s) into virulence during vaccination. LAIVs acquired multiple attenuation mutations among various internal genes and proven safe as seasonal influenza vaccines (especially for A/Ann Arbor strain as the master strain for FluMist). However, genetically engineered LAIVs with a limited set of attenuation mutations, e.g., NS1deletion or elastase-dependent HA cleavage (Talon et al., 2000; Stech et al., 2005), may require additional monitoring on safety.

Defining the precise correlates of protection represents the most challenging step in the development of a UIV (Erbelding et al., 2018). Significant efforts were made to identify the protection mechanisms of HA stalk-based vaccines, suggesting that direct neutralization in combination with Fc-dependent indirect effector mechanisms mediated by stalk antibodies were the primary correlates of protection. In contrast to HA stalkbased vaccines, LAIVs elicit multiple immunological factors including serum IgG antibodies and mucosal IgA antibodies to surface antigens (HA, NA, and M2) and cell-mediated immunity to internal antigens, synergistically contributing to protection. However, their quantitative relationship to protection has not been determined, not even for homologous protection (Sridhar et al., 2015; Mohn et al., 2018), let alone for cross-protection against heterologous infection. The development of standardized assays to quantitatively measure $\mathrm{T}$ cell-mediated protection is particularly challenging, as the magnitude and the subset of $\mathrm{T}$ cells critical for protection is likely to differ according to strains of LAIV and challenge viruses. Further, mucosal IgA antibodies are believed to correlate with cross-protection, but it is still challenging to measure the neutralizing activity or effector functions of mucosal IgA antibodies. The complicated nature of LAIV-induced immunity, including non-neutralizing antibodies and diverse subsets of $\mathrm{T}$ cells, present a bottleneck to identifying precise correlates of protection.

Another important aspect of LAIV-based strategies lies on the LAIV strains. During the past century, H1N1 and H3N2 subtypes of influenza A viruses were the most prevalent strains in humans, causing annual epidemics as well as occasional pandemics, except for the temporal circulation of H2N2 during 1957-1968 (Kilbourne, 2006) (Figure 6). Accordingly, seasonal influenza vaccines are recommended to include H1N1 and H3N2 vaccine antigens for more than 40 years since 1977 . Therefore, it is likely that most contemporary population has preexisting $\mathrm{T}$ cell immunity to $\mathrm{H} 1 \mathrm{~N} 1$ and $\mathrm{H} 3 \mathrm{~N} 2$ strains through natural infections or vaccinations. It should be remembered that currently licensed LAIVs (A/Ann Arbor/6/60 ca and A/Leningrad/134/17/57 ca) are of H2N2 subtypes. Probably, the nature of strain itself does not really matter for seasonal influenza vaccine, for which strain-specific immunity is focused on the surface HA antigen. However, for eliciting cross-protection, the role of conserved region become important (see section HA stalk-based UIV approaches, Conserved targets in HA other than stalk, NA as a novel target for a UIV for HA/NA and section T cell immunity as an essential factor for truly universal influenza protection for internal proteins). It is likely that human populations under 50 years of age (born after 1968 when H2N2 became extinct) has little preexisting immunity against $\mathrm{H} 2 \mathrm{~N} 2$, but predominantly against $\mathrm{H} 1 \mathrm{~N} 1$ and $\mathrm{H} 3 \mathrm{~N} 2$ viruses. It will therefore be worthwhile to examine whether cold-adapted LAIVs of H1N1 (Jang et al., 2018) or H3N2 origin (non-existent, to our knowledge) offer a beneficial effects on boosting the preexisting cross-reactive $\mathrm{T}$ cell immunity and antibody effector functions (section Mode of protection by a UIV; Figure 3).

As for IBVs, two distinct lineages diverged and circulated after 1985, which necessitates the incorporation of Victoria-like and Yamagata-like lineages in seasonal influenza vaccines. This leads us to raise a possibility of using an ancestral influenza B strain (such as B/Lee/40) before divergence into two different lineages as a UIV candidate for IBVs. Establishing new cold-adapted LAIV strains is a time-consuming and laborious. However, recent advances in reverse genetics and rational approaches to attenuate viral virulence have enabled the rapid conversion of a wild type virus into a novel LAIV strain. These approaches include NS1 truncation, elastase-dependent HA cleavage, caspase-dependent NP and NS1 cleavage, microRNA-mediated silencing, and codon deoptimization (Talon et al., 2000; Stech et al., 2005; Coleman et al., 2008; Perez et al., 2009; Jang et al., 2013b).

The redirection of host immune responses from surface proteins toward internal proteins may be achieved by rational vaccination strategies with LAIVs. For example, the down regulation of expression levels of HA or NA in a LAIV (Yang et al., 2013) is likely to result in preferable induction of $\mathrm{T}$ cell immunity to internal proteins. Alternatively, vaccination with LAIV carrying HA from non-human influenza viruses such as H5 or $\mathrm{H} 9$ may be effective at boosting preexisting $\mathrm{T}$ cell immunity to internal proteins in humans. Given the cross-reactivity of $\mathrm{T}$ cell immunity between IAVs and IBVs, A type LAIVs and B type LAIVs may be administered as a bivalent formulation or by sequential vaccination to induce improved protection.

\section{OTHER STRATEGIES FOR UIVs}

A number of alternative strategies are being investigated for their potential to serve as a UIV platform. First approach is to use infection-competent but replication-defective viruses. For instance, the M2 knock-out influenza virus (M2SR) rescued from M2-producing cells is able to infect cells but does not produce progeny virus due to the lack of functional M2 protein. The M2SR was shown to induce strong cell-mediated and humoral immunity and to provide broad protection against both homologous and heterologous influenza virus challenge in mice and ferrets (Sarawar et al., 2016; Hatta et al., 2017, 2018). A conceptually similar to M2SR, PB2 knock-out influenza virus could be produced in PB2-expressing cells as a vaccine. 


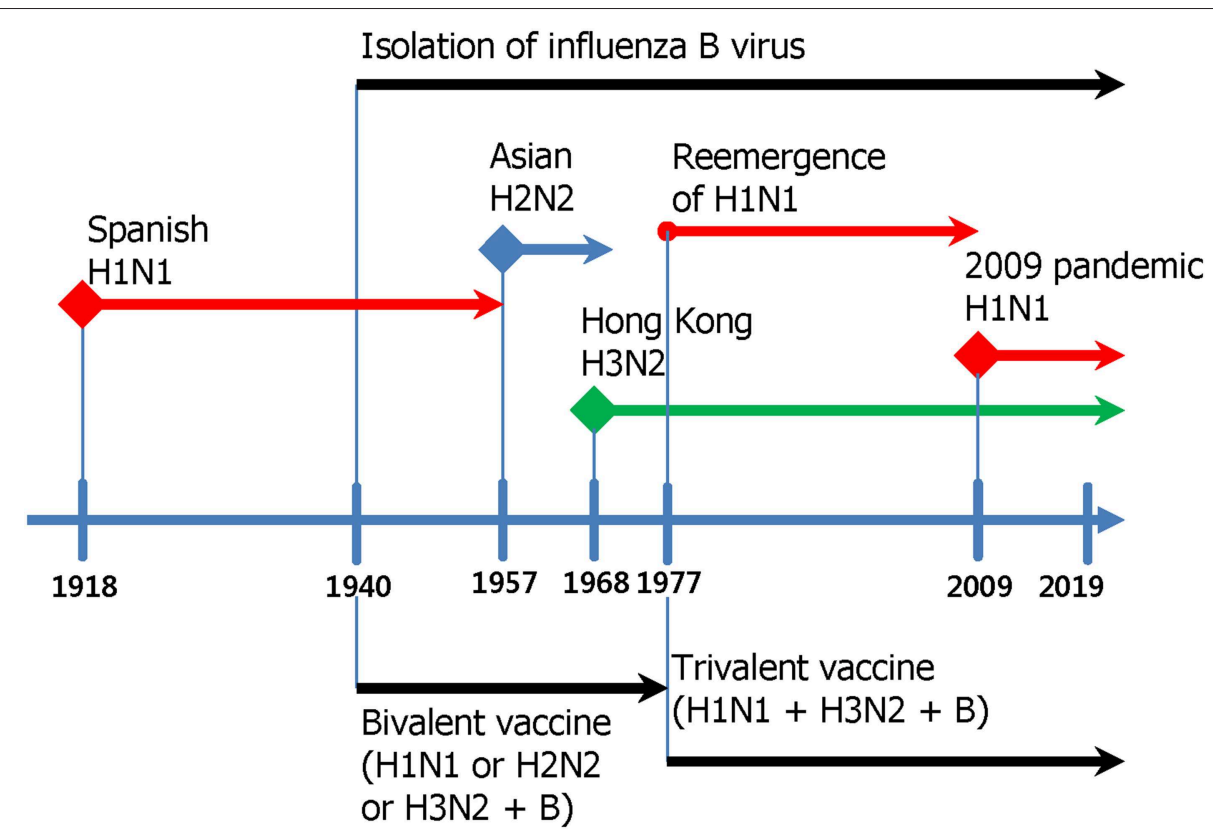

FIGURE 6 | Co-evolution of influenza viruses and influenza vaccines. Within the past century, there were four influenza pandemics; 1918 Spanish flu (H1N1), 1957 Asian flu (H2N2), 1968 Hong Kong flu (H3N2), and 2009 swine flu (H1N1) (Saunders-Hastings and Krewski, 2016). The 1918 Spanish flu (H1N1) evolved into seasonal influenza strain and had circulated for $\sim 40$ years until the next pandemic by 1957 Asian flu (H2N2), which after $\sim 10$ years of circulation was replaced by 1968 Hong Kong flu (H3N2). The 1968 Hong Kong flu (H3N2) has circulated until now as seasonal influenza strains. In 1977, H1N1 strain reemerged and was replaced by the 2009 swine flu ( $\mathrm{H} 1 \mathrm{~N} 1)$, which evolved into seasonal influenza strains circulating until now. Thus, H1N1 and H3N2 strains began to co-circulate from 1977. After the reemergence of $\mathrm{H} 1 \mathrm{~N} 1$ in 1977 , World Health Organization has issued recommendations for trivalent vaccine composition containing $\mathrm{A} / \mathrm{H} 1 \mathrm{~N} 1$, $\mathrm{A} / \mathrm{H} 3 \mathrm{~N} 2$, and $\mathrm{B}$ strains (Hannoun, 2013).

The protection efficacy of $\mathrm{PB} 2-\mathrm{KO}$ vaccine was tested against diverse influenza strains in mice (Victor et al., 2012; Uraki et al., 2013; Ui et al., 2017). Pseudotyped influenza A virus also presents a similar replication-incompetent virus approach. The pseudotyped influenza virus lacking HA produced in HAexpressing cells can infect cells and express all the viral proteins except for HA. Studies have shown that the vaccination of mice and ferrets with the pseudotyped influenza virus generated a vigorous $\mathrm{T}$ cell response and reduced lung viral loads and weight loss after challenge with homologous and heterologous influenza viruses (Powell et al., 2012; Baz et al., 2015). These approaches based on replication-defective viruses should be rigorously evaluated for safety, considering potential reversion into virulence by acquiring the wild type gene by reassortment with circulating viruses (Lowen, 2017).

Secondly, mRNA vaccines have emerged as a promising alternative to conventional vaccine platforms against various infectious diseases including the influenza virus (Pardi et al., 2018a). Initially, the mRNA vaccines successfully induced protective $\mathrm{B}$ cell and $\mathrm{T}$ cell immune response in mice, ferrets, and pigs (Petsch et al., 2012). In subsequent studies, mRNA vaccines encoding $\mathrm{HA}$ induced neutralizing antibodies and $\mathrm{T}$ cell immunity essential for heterologous protection in mice and ferrets (Brazzoli et al., 2016). Notably, mRNA vaccines encoding HA elicited HA stalk antibodies in mice, rabbits, and ferrets, and the stalk antibody responses were associated with protection against homologous and heterologous influenza virus infection in mice (Pardi et al., 2018b), depicting promising potential as a UIV platform.

\section{CONCLUSIONS AND PROSPECTS}

During the past few years, several critically important issues have emerged in developing a UIV. While identification of a number of broadly protective antibodies presents an optimistic prospect for pan-influenza therapeutics, induction of such antibodies at a sufficiently protective level by vaccination has not been accomplished yet. A variety of viral targets have been identified to induce broad protection, including M2e and the conserved regions in the HA, such as stalk, RBS, and VE, and the longneglected NA has emerged as an essential target for durable and broad protection. In virtually all cases, the rationale for broad protection is to redirect the immune responses from the variable immunodominant regions to conserved immunosubdominant regions. While effective in eliciting cross-protection, concerns were raised to non-neutralizing antibodies that potentially trigger the enhancement of disease. T-cell immunity has also been considered as an important correlate of cross-protection. LAIVs are able to induce multifaceted immune response and thus have increasingly received close attention as a promising vaccine platform, either alone, or in boosting format. Preexisting immunity or immunologic imprinting, established by prior exposure to influenza by infection or vaccination, may influence 
or thwart the desired breadth of immune response by UIVs. Therefore, disparities may exist between pre-clinical evaluation of a UIV without due recognition of immune imprinting and human challenge studies. Lastly, the correlates of protection and their precise molecular mechanisms have not been determined yet, which remains a significant gap between development and licensing of a UIV. Given the limited antigenic diversity of IBVs among humans and the lack of animal reservoir, paninfluenza $B$ virus vaccine may be attainable in the near future. On the other hand, IAVs continually change their antigenicity via antigenic drift and shift and zoonotic spillover from animal reservoirs, requiring multi-faceted immune arms to increase the breadth of protection. Judicious choice of antigens and their efficient designing to confer a broad protection for a prolonged period are required to counterfeit the immune evasion and

\section{REFERENCES}

Adar, Y., Singer, Y., Levi, R., Tzehoval, E., Perk, S., Banet-Noach, C., et al. (2009). A universal epitope-based influenza vaccine and its efficacy against H5N1. Vaccine 27, 2099-2107. doi: 10.1016/j.vaccine.2009.02.011

Ambrose, C. S., and Levin, M. J. (2012). The rationale for quadrivalent influenza vaccines. Hum. Vaccin Immunother. 8, 81-88. doi: 10.4161/hv.8.1.17623

Ana-Sosa-Batiz, F., Vanderven, H., Jegaskanda, S., Johnston, A., Rockman, S., Laurie, K., et al. (2016). Influenza-specific antibody-dependent phagocytosis. PLoS ONE 11:e0154461. doi: 10.1371/journal.pone.0154461

Anderson, C. S., Ortega, S., Chaves, F. A., Clark, A. M., Yang, H., Topham, D. J., et al. (2017). Natural and directed antigenic drift of the H1 influenza virus hemagglutinin stalk domain. Sci. Rep. 7:14614. doi: 10.1038/s41598-017-14931-7

Antrobus, R. D., Lillie, P. J., Berthoud, T. K., Spencer, A. J., McLaren, J. E., Ladell, K., et al. (2012). A T cell-inducing influenza vaccine for the elderly: safety and immunogenicity of MVA-NP+M1 in adults aged over 50 years. PLoS ONE 7:e48322. doi: 10.1371/journal.pone.0048322

Arevalo, M. T., Li, J., Diaz-Arevalo, D., Chen, Y., Navarro, A., Wu, L., et al. (2017). A dual purpose universal influenza vaccine candidate confers protective immunity against anthrax. Immunology 150, 276-289. doi: 10.1111/imm.12683

Assarsson, E., Bui, H. H., Sidney, J., Zhang, Q., Glenn, J., Oseroff, C., et al. (2008). Immunomic analysis of the repertoire of T-cell specificities for influenza A virus in humans. J. Virol. 82, 12241-12251. doi: 10.1128/JVI.01563-08

Asthagiri Arunkumar, G., Ioannou, A., Wohlbold, T. J., Meade, P., Aslam, S., Amanat, F., et al. (2019). Broadly cross-reactive, nonneutralizing antibodies against influenza B virus hemagglutinin demonstrate effector functiondependent protection against lethal viral challenge in mice. J. Virol. 93:e01696-18. doi: 10.1128/JVI.01696-18

Babon, J. A., Cruz, J., Ennis, F. A., Yin, L., and Terajima, M. (2012). A human $\mathrm{CD} 4+\mathrm{T}$ cell epitope in the influenza hemagglutinin is cross-reactive to influenza A virus subtypes and to influenza B virus. J. Virol. 86, 9233-9243. doi: 10.1128/JVI.06325-11

Bajic, G., Maron, M. J., Adachi, Y., Onodera, T., McCarthy, K. R., McGee, C. E., et al. (2019a). Influenza antigen engineering focuses immune responses to a subdominant but broadly protective viral epitope. Cell Host Microbe 25, 827-835.e826. doi: 10.1016/j.chom.2019.04.003

Bajic, G., van der Poel, C. E., Kuraoka, M., Schmidt, A. G., Carroll, M. C., Kelsoe, G., et al. (2019b). Autoreactivity profiles of influenza hemagglutinin broadly neutralizing antibodies. Sci. Rep. 9:3492. doi: 10.1038/s41598-019-40175-8

Bangaru, S., Zhang, H., Gilchuk, I. M., Voss, T. G., Irving, R. P., Gilchuk, P., et al. (2018). A multifunctional human monoclonal neutralizing antibody that targets a unique conserved epitope on influenza HA. Nat. Commun. 9:2669. doi: 10.1038/s41467-018-04704-9

Baz, M., Boonnak, K., Paskel, M., Santos, C., Powell, T., Townsend, A., et al. (2015). Nonreplicating influenza A virus vaccines confer broad protection against lethal challenge. MBio 6:e01487-e01415. doi: 10.1128/mBio.01487-15 provide a truly universal protection against the ever-changing influenza viruses.

\section{AUTHOR CONTRIBUTIONS}

BS designed and conceived the review. YJ and BS investigated the literature and wrote the manuscript.

\section{FUNDING}

This work was supported by grants from National Research Foundation of Korea (NRF-2018R1D1A1B07048881; NRF2018M3A9H4079358) and also supported by grant from the Ministry of Food and Drug Safety of the Republic of Korea (19172MFDS255).

Belshe, R. B., Gruber, W. C., Mendelman, P. M., Cho, I., Reisinger, K., Block, S. L., et al. (2000). Efficacy of vaccination with live attenuated, cold-adapted, trivalent, intranasal influenza virus vaccine against a variant (A/Sydney) not contained in the vaccine. J. Pediatr. 136, 168-175. doi: 10.1016/S0022-3476(00)70097-7

Benjamin, E., Wang, W., McAuliffe, J. M., Palmer-Hill, F. J., Kallewaard, N. L., Chen, Z., et al. (2014). A broadly neutralizing human monoclonal antibody directed against a novel conserved epitope on the influenza virus H3 hemagglutinin globular head. J. Virol. 88, 6743-6750. doi: 10.1128/JVI.03562-13

Bernasconi, V., Bernocchi, B., Ye, L., Le, M. Q., Omokanye, A., Carpentier, R., et al. (2018). Porous nanoparticles with self-adjuvanting M2e-fusion protein and recombinant hemagglutinin provide strong and broadly protective immunity against influenza virus infections. Front. Immunol. 9:2060. doi: 10.3389/fimmu.2018.02060

Bessa, J., Schmitz, N., Hinton, H. J., Schwarz, K., Jegerlehner, A., and Bachmann, M. F. (2008). Efficient induction of mucosal and systemic immune responses by virus-like particles administered intranasally: implications for vaccine design. Eur. J. Immunol. 38, 114-126. doi: 10.1002/eji.200636959

Bodewes, R., Kreijtz, J. H., Geelhoed-Mieras, M. M., van Amerongen, G., Verburgh, R. J., van Trierum, S. E., et al. (2011). Vaccination against seasonal influenza $\mathrm{A} / \mathrm{H} 3 \mathrm{~N} 2$ virus reduces the induction of heterosubtypic immunity against influenza A/H5N1 virus infection in ferrets. J. Virol. 85, 2695-2702. doi: 10.1128/JVI.02371-10

Bragstad, K., Vinner, L., Hansen, M. S., Nielsen, J., and Fomsgaard, A. (2013). A polyvalent influenza A DNA vaccine induces heterologous immunity and protects pigs against pandemic $\mathrm{A}(\mathrm{H} 1 \mathrm{~N} 1)$ pdm09 virus infection. Vaccine 31, 2281-2288. doi: 10.1016/j.vaccine.2013. 02.061

Brandenburg, B., Koudstaal, W., Goudsmit, J., Klaren, V., Tang, C., Bujny, M. V., et al. (2013). Mechanisms of hemagglutinin targeted influenza virus neutralization. PLoS ONE 8:e80034. doi: 10.1371/journal.pone.0080034

Brazzoli, M., Magini, D., Bonci, A., Buccato, S., Giovani, C., Kratzer, R., et al. (2016). Induction of broad-based immunity and protective efficacy by selfamplifying mRNA vaccines encoding influenza virus hemagglutinin. J. Virol. 90, 332-344. doi: 10.1128/JVI.01786-15

Carter, D. M., Darby, C. A., Lefoley, B. C., Crevar, C. J., Alefantis, T., Oomen, R., et al. (2016). Design and characterization of a computationally optimized broadly reactive hemagglutinin vaccine for H1N1 Influenza Viruses. J. Virol. 90, 4720-4734. doi: 10.1128/JVI.03152-15

Chai, N., Swem, L. R., Park, S., Nakamura, G., Chiang, N., Estevez, A., et al. (2017). A broadly protective therapeutic antibody against influenza B virus with two mechanisms of action. Nat. Commun. 8:14234. doi: 10.1038/ncomms14234

Chai, N., Swem, L. R., Reichelt, M., Chen-Harris, H., Luis, E., Park, S., et al. (2016). Two escape mechanisms of influenza A virus to a broadly neutralizing stalk-binding antibody. PLoS Pathog. 12:e1005702. doi: 10.1371/journal.ppat.1005702 
Chen, Y. Q., Lan, L. Y., Huang, M., Henry, C., and Wilson, P. C. (2019). Hemagglutinin stalk-reactive antibodies interfere with influenza virus neuraminidase activity by steric hindrance. J. Virol. 93:e01526-18. doi: 10.1128/JVI.01526-18

Chen, Y. Q., Wohlbold, T. J., Zheng, N. Y., Huang, M., Huang, Y., Neu, K. E., et al. (2018). Influenza infection in humans induces broadly cross-reactive and protective neuraminidase-reactive antibodies. Cell 173, 417-429.e410. doi: 10.1016/j.cell.2018.03.030

Cheng, X., Zengel, J. R., Suguitan, A. L. Jr., Xu, Q., Wang, W., Lin, J., et al. (2013). Evaluation of the humoral and cellular immune responses elicited by the live attenuated and inactivated influenza vaccines and their roles in heterologous protection in ferrets. J. Infect. Dis. 208, 594-602. doi: 10.1093/infdis/jit207

Clemens, E. B., van de Sandt, C., Wong, S. S., Wakim, L. M., and Valkenburg, S. A. (2018). Harnessing the power of T cells: the promising hope for a universal influenza vaccine. Vaccines 6:18. doi: 10.3390/vaccines6020018

Cohen, J. (1993). Naked DNA points way to vaccines. Science 259, 1691-1692. doi: $10.1126 /$ science. 8456293

Cohen, M., Zhang, X. Q., Senaati, H. P., Chen, H. W., Varki, N. M., Schooley, R. T., et al. (2013). Influenza A penetrates host mucus by cleaving sialic acids with neuraminidase. Virol. J. 10:321. doi: 10.1186/1743-422X-10-321

Coleman, J. R., Papamichail, D., Skiena, S., Futcher, B., Wimmer, E., and Mueller, S. (2008). Virus attenuation by genome-scale changes in codon pair bias. Science 320, 1784-1787. doi: 10.1126/science.1155761

Corbett, K. S., Moin, S. M., Yassine, H. M., Cagigi, A., Kanekiyo, M., BoyogluBarnum, S., et al. (2019). Design of nanoparticulate group 2 influenza virus hemagglutinin stem antigens that activate unmutated ancestor B cell receptors of broadly neutralizing antibody lineages. MBio 10:e2810-18. doi: $10.1128 / \mathrm{mBio} .02810-18$

Corti, D., Voss, J., Gamblin, S. J., Codoni, G., Macagno, A., Jarrossay, D., et al. (2011). A neutralizing antibody selected from plasma cells that binds to group 1 and group 2 influenza A hemagglutinins. Science 333, 850-856. doi: $10.1126 /$ science. 1205669

Couch, R. B., Atmar, R. L., Franco, L. M., Quarles, J. M., Wells, J., Arden, N., et al. (2013). Antibody correlates and predictors of immunity to naturally occurring influenza in humans and the importance of antibody to the neuraminidase. $J$. Infect. Dis. 207, 974-981. doi: 10.1093/infdis/jis935

Crevar, C. J., Carter, D. M., Lee, K. Y., and Ross, T. M. (2015). Cocktail of $\mathrm{H} 5 \mathrm{~N} 1 \mathrm{COBRA} \mathrm{HA}$ vaccines elicit protective antibodies against $\mathrm{H} 5 \mathrm{~N} 1$ viruses from multiple clades. Hum. Vaccin Immunother. 11, 572-583. doi: 10.1080/21645515.2015.1012013

Crowe, J. E. Jr. (2018). Is it possible to develop a "universal" influenza virus vaccine? potential for a universal influenza vaccine. Cold Spring Harb. Perspect. Biol. 10:a029496. doi: 10.1101/cshperspect.a029496

De Filette, M., Fiers, W., Martens, W., Birkett, A., Ramne, A., Lowenadler, B., et al. (2006). Improved design and intranasal delivery of an M2e-based human influenza A vaccine. Vaccine 24, 6597-6601. doi: 10.1016/j.vaccine.2006. 05.082

Deng, L., Cho, K. J., Fiers, W., and Saelens, X. (2015a). M2e-based universal influenza a vaccines. Vaccines 3, 105-136. doi: 10.3390/vaccines3010105

Deng, L., Ibanez, L. I., Van den Bossche, V., Roose, K., Youssef, S. A., de Bruin, A., et al. (2015b). Protection against influenza A virus challenge with M2e-displaying filamentous Escherichia coli phages. PLoS ONE 10:e126650. doi: 10.1371/journal.pone.0126650

Deng, L., Mohan, T., Chang, T. Z., Gonzalez, G. X., Wang, Y., Kwon, Y. M., et al. (2018). Double-layered protein nanoparticles induce broad protection against divergent influenza A viruses. Nat. Commun. 9:359. doi: 10.1038/s41467-017-02725-4

Denis, J., Acosta-Ramirez, E., Zhao, Y., Hamelin, M. E., Koukavica, I., Baz, M., et al. (2008). Development of a universal influenza A vaccine based on the M2e peptide fused to the papaya mosaic virus (PapMV) vaccine platform. Vaccine 26, 3395-3403. doi: 10.1016/j.vaccine.2008.04.052

DeZure, A. D., Coates, E. E., Hu, Z., Yamshchikov, G. V., Zephir, K. L., Enama, M. E., et al. (2017). An avian influenza H7 DNA priming vaccine is safe and immunogenic in a randomized phase I clinical trial. NPJ Vaccines 2:15. doi: 10.1038/s41541-017-0016-6

DiLillo, D. J., Palese, P., Wilson, P. C., and Ravetch, J. V. (2016). Broadly neutralizing anti-influenza antibodies require $\mathrm{Fc}$ receptor engagement for in vivo protection. J. Clin. Invest. 126, 605-610. doi: 10.1172/JCI84428
DiLillo, D. J., Tan, G. S., Palese, P., and Ravetch, J. V. (2014). Broadly neutralizing hemagglutinin stalk-specific antibodies require $\mathrm{F} c \gamma \mathrm{R}$ interactions for protection against influenza virus in vivo. Nat. Med. 20, 143-151. doi: $10.1038 / \mathrm{nm} .3443$

Doyle, T. M., Hashem, A. M., Li, C., Van Domselaar, G., Larocque, L., Wang, J., et al. (2013a). Universal anti-neuraminidase antibody inhibiting all influenza A subtypes. Antiviral Res. 100, 567-574. doi: 10.1016/j.antiviral.2013.09.018

Doyle, T. M., Li, C., Bucher, D. J., Hashem, A. M., Van Domselaar, G., Wang, J., et al. (2013b). A monoclonal antibody targeting a highly conserved epitope in influenza B neuraminidase provides protection against drug resistant strains. Biochem. Biophys. Res. Commun. 441, 226-229. doi: 10.1016/j.bbrc.2013.10.041

Dreyfus, C., Laursen, N. S., Kwaks, T., Zuijdgeest, D., Khayat, R., Ekiert, D. C., et al. (2012). Highly conserved protective epitopes on influenza B viruses. Science 337, 1343-1348. doi: 10.1126/science.1222908

Duan, S., and Thomas, P. G. (2016). Balancing immune protection and immune pathology by $\mathrm{CD} 8(+)$ T-cell responses to influenza infection. Front. Immunol. 7:25. doi: 10.3389/fimmu.2016.00025

Ducatez, M. F., Bahl, J., Griffin, Y., Stigger-Rosser, E., Franks, J., Barman, S., et al. (2011). Feasibility of reconstructed ancestral H5N1 influenza viruses for cross-clade protective vaccine development. Proc. Natl. Acad. Sci. U.S.A. 108, 349-354. doi: 10.1073/pnas.1012457108

Ducatez, M. F., Webb, A., Crumpton, J. C., and Webby, R. J. (2013). Long-term vaccine-induced heterologous protection against $\mathrm{H} 5 \mathrm{~N} 1$ influenza viruses in the ferret model. Influenza Other Respir. Viruses 7, 506-512. doi: 10.1111/j.1750-2659.2012.00423.x

Dykes, A. C., Cherry, J. D., and Nolan, C. E. (1980). A clinical, epidemiologic, serologic, and virologic study of influenza $\mathrm{C}$ virus infection. Arch. Intern. Med. 140, 1295-1298. doi: 10.1001/archinte.1980.00330210043021

Easterbrook, J. D., Schwartzman, L. M., Gao, J., Kash, J. C., Morens, D. M., Couzens, L., et al. (2012). Protection against a lethal H5N1 influenza challenge by intranasal immunization with virus-like particles containing 2009 pandemic H1N1 neuraminidase in mice. Virology 432, 39-44. doi: 10.1016/j.virol.2012.06.003

Eggink, D., Goff, P. H., and Palese, P. (2014). Guiding the immune response against influenza virus hemagglutinin toward the conserved stalk domain by hyperglycosylation of the globular head domain. J. Virol. 88, 699-704. doi: 10.1128/JVI.02608-13

Eichelberger, M. C., and Monto, A. S. (2019). Neuraminidase, the forgotten surface antigen, emerges as an influenza vaccine target for broadened protection. $J$. Infect. Dis. 219(Suppl 1), S75-80. doi: 10.1093/infdis/jiz017

Ekiert, D. C., Bhabha, G., Elsliger, M. A., Friesen, R. H., Jongeneelen, M., Throsby, M., et al. (2009). Antibody recognition of a highly conserved influenza virus epitope. Science 324, 246-251. doi: 10.1126/science.1171491

Ekiert, D. C., Friesen, R. H., Bhabha, G., Kwaks, T., Jongeneelen, M., Yu, W., et al. (2011). A highly conserved neutralizing epitope on group 2 influenza A viruses. Science 333, 843-850. doi: 10.1126/science.1204839

Ekiert, D. C., Kashyap, A. K., Steel, J., Rubrum, A., Bhabha, G., Khayat, R., et al. (2012). Cross-neutralization of influenza A viruses mediated by a single antibody loop. Nature 489, 526-532. doi: 10.1038/nature11414

Eliasson, D. G., El Bakkouri, K., Schon, K., Ramne, A., Festjens, E., Lowenadler, B., et al. (2008). CTA1-M2e-DD: a novel mucosal adjuvant targeted influenza vaccine. Vaccine 26, 1243-1252. doi: 10.1016/j.vaccine.2007.12.027

Eliasson, D. G., Omokanye, A., Schon, K., Wenzel, U. A., Bernasconi, V., Bemark, M., et al. (2018). M2e-tetramer-specific memory CD4 T cells are broadly protective against influenza infection. Mucosal Immunol. 11, 273-289. doi: $10.1038 / \mathrm{mi} .2017 .14$

Erbelding, E. J., Post, D. J., Stemmy, E. J., Roberts, P. C., Augustine, A. D., Ferguson, S., et al. (2018). A universal influenza vaccine: the strategic plan for the National Institute of Allergy and Infectious Diseases. J. Infect. Dis 218, 347-354. doi: 10.1093/infdis/jiy103

Ermler, M. E., Kirkpatrick, E., Sun, W., Hai, R., Amanat, F., Chromikova, V., et al. (2017). Chimeric hemagglutinin constructs induce broad protection against influenza B virus challenge in the mouse model. J. Virol. 91:e00286-17. doi: 10.1128/JVI.00286-17

Estrada, L. D., and Schultz-Cherry, S. (2019). Development of a universal influenza vaccine. J. Immunol. 202, 392-398. doi: 10.4049/jimmunol.1801054

Folegatti, P. M., Bellamy, D., Flaxman, A., Mair, C., Ellis, C., Ramon, R. L., et al (2019). Safety and immunogenicity of the heterosubtypic influenza A vaccine 
MVA-NP+M1 mnufactured on the AGE1.CR.pIX avian cell line. Vaccines 7:33. doi: 10.3390/vaccines7010033

Forrest, B. D., Pride, M. W., Dunning, A. J., Capeding, M. R., Chotpitayasunondh, T., Tam, J. S., et al. (2008). Correlation of cellular immune responses with protection against culture-confirmed influenza virus in young children. Clin. Vaccine Immunol. 15, 1042-1053. doi: 10.1128/CVI.00397-07

Friesen, R. H., Lee, P. S., Stoop, E. J., Hoffman, R. M., Ekiert, D. C., Bhabha, G., et al. (2014). A common solution to group 2 influenza virus neutralization. Proc. Natl. Acad. Sci. U.S.A. 111, 445-450. doi: 10.1073/pnas.1319058110

Gao, X., Wang, W., Li, Y., Zhang, S., Duan, Y., Xing, L., et al. (2013). Enhanced influenza VLP vaccines comprising matrix-2 ectodomain and nucleoprotein epitopes protects mice from lethal challenge. Antiviral Res. 98, 4-11. doi: 10.1016/j.antiviral.2013.01.010

Gauger, P. C., Vincent, A. L., Loving, C. L., Lager, K. M., Janke, B. H., Kehrli, M. E. Jr., et al. (2011). Enhanced pneumonia and disease in pigs vaccinated with an inactivated human-like (delta-cluster) H1N2 vaccine and challenged with pandemic 2009 H1N1 influenza virus. Vaccine 29, 2712-2719. doi: $10.1016 / j . v a c c i n e .2011 .01 .082$

Gianfrani, C., Oseroff, C., Sidney, J., Chesnut, R. W., and Sette, A. (2000). Human memory CTL response specific for influenza A virus is broad and multispecific. Hum. Immunol. 61, 438-452. doi: 10.1016/S0198-8859(00)00105-1

Giles, B. M., and Ross, T. M. (2011). A computationally optimized broadly reactive antigen (COBRA) based H5N1 VLP vaccine elicits broadly reactive antibodies in mice and ferrets. Vaccine 29, 3043-3054. doi: 10.1016/j.vaccine.2011.01.100

Gostic, K. M., Ambrose, M., Worobey, M., and Lloyd-Smith, J. O. (2016). Potent protection against $\mathrm{H} 5 \mathrm{~N} 1$ and $\mathrm{H} 7 \mathrm{~N} 9$ influenza via childhood hemagglutinin imprinting. Science 354, 722-726. doi: 10.1126/science.aag1322

Gras, S., Kedzierski, L., Valkenburg, S. A., Laurie, K., Liu, Y. C., Denholm, J. T., et al. (2010). Cross-reactive CD8 T-cell immunity between the pandemic H1N1-2009 and H1N1-1918 influenza A viruses. Proc. Natl. Acad. Sci. U.S.A. 107, 12599-12604. doi: 10.1073/pnas.10072 70107

Graves, P. N., Schulman, J. L., Young, J. F., and Palese, P. (1983). Preparation of influenza virus subviral particles lacking the HA1 subunit of hemagglutinin: Unmasking of cross-reactive HA2 determinants. Virology 126, 106-116. doi: 10.1016/0042-6822(83)90465-8

Guilliams, M., Bruhns, P., Saeys, Y., Hammad, H., and Lambrecht, B. N. (2014). The function of Fcgamma receptors in dendritic cells and macrophages. Nat. Rev. Immunol. 14, 94-108. doi: 10.1038/nri3582

Guo, Y., He, L., Song, N., Li, P., Sun, S., Zhao, G., et al. (2017). Highly conserved $\mathrm{M} 2 \mathrm{e}$ and hemagglutinin epitope-based recombinant proteins induce protection against influenza virus infection. Microbes Infect. 19, 641-647. doi: 10.1016/j.micinf.2017.08.010

Ha, Y., Stevens, D. J., Skehel, J. J., and Wiley, D. C. (2002). H5 avian and H9 swine influenza virus haemagglutinin structures: possible origin of influenza subtypes. EMBO J. 21, 865-875. doi: 10.1093/emboj/21.5.865

Hai, R., Krammer, F., Tan, G. S., Pica, N., Eggink, D., Maamary, J., et al. (2012). Influenza viruses expressing chimeric hemagglutinins: globular head and stalk domains derived from different subtypes. J. Virol. 86, 5774-5781. doi: 10.1128/JVI.00137-12

Hannoun, C. (2013). The evolving history of influenza viruses and influenza vaccines. Exp. Rev. Vaccines 12, 1085-1094. doi: 10.1586/14760584.2013.824709

Hashemi, H., Pouyanfard, S., Bandehpour, M., Noroozbabaei, Z., Kazemi, B., Saelens, X., et al. (2012). Immunization with M2e-displaying T7 bacteriophage nanoparticles protects against influenza A virus challenge. PLOS ONE 7:e45765. doi: 10.1371/journal.pone. 0045765

Hashimoto, Y., Moki, T., Takizawa, T., Shiratsuchi, A., and Nakanishi, Y. (2007). Evidence for phagocytosis of influenza virus-infected, apoptotic cells by neutrophils and macrophages in mice. J. Immunol. 178, 2448-2457. doi: $10.4049 /$ jimmunol.178.4.2448

Hatta, Y., Boltz, D., Sarawar, S., Kawaoka, Y., Neumann, G., and Bilsel, P. (2017). M2SR, a novel live influenza vaccine, protects mice and ferrets against highly pathogenic avian influenza. Vaccine 35, 4177-4183. doi: 10.1016/j.vaccine.2017.06.039

Hatta, Y., Boltz, D., Sarawar, S., Kawaoka, Y., Neumann, G., and Bilsel, P. (2018). Novel influenza vaccine M2SR protects against drifted H1N1 and H3N2 influenza virus challenge in ferrets with pre-existing immunity. Vaccine 36, 5097-5103. doi: 10.1016/j.vaccine.2018.06.053
Hayward, A. C., Wang, L., Goonetilleke, N., Fragaszy, E. B., Bermingham, A., Copas, A., et al. (2015). Natural T cell-mediated protection against seasonal and pandemic influenza. Results of the Flu watch cohort study. Am. J. Respir. Crit. Care Med. 191, 1422-1431. doi: 10.1164/rccm.201411-1988OC

He, X. S., Holmes, T. H., Zhang, C., Mahmood, K., Kemble, G. W., Lewis, D. B., et al. (2006). Cellular immune responses in children and adults receiving inactivated or live attenuated influenza vaccines. J. Virol. 80, 11756-11766. doi: 10.1128/JVI.01460-06

Hemann, E. A., Kang, S. M., and Legge, K. L. (2013). Protective CD8 T cell-mediated immunity against influenza A virus infection following influenza virus-like particle vaccination. J. Immunol. 191, 2486-2494. doi: 10.4049/jimmunol.1300954

Henry Dunand, C. J., Leon, P. E., Kaur, K., Tan, G. S., Zheng, N. Y., Andrews, S., et al. (2015). Preexisting human antibodies neutralize recently emerged H7N9 influenza strains. J. Clin. Invest. 125, 1255-1268. doi: 10.1172/JCI74374

Henry, C., Palm, A. E., Krammer, F., and Wilson, P. C. (2018). From original antigenic sin to the universal influenza virus vaccine. Trends Immunol. 39, 70-79. doi: 10.1016/j.it.2017.08.003

Hessel, A., Savidis-Dacho, H., Coulibaly, S., Portsmouth, D., Kreil, T. R., Crowe, B. A., et al. (2014). MVA vectors expressing conserved influenza proteins protect mice against lethal challenge with $\mathrm{H} 5 \mathrm{~N} 1, \mathrm{H} 9 \mathrm{~N} 2$ and $\mathrm{H} 7 \mathrm{~N} 1$ viruses. PLOS ONE 9:e88340. doi: 10.1371/journal.pone.0088340

Hillaire, M. L., van Trierum, S. E., Kreijtz, J. H., Bodewes, R., Geelhoed-Mieras, M. M., Nieuwkoop, N. J., et al. (2011). Cross-protective immunity against influenza pH1N1 2009 viruses induced by seasonal influenza A (H3N2) virus is mediated by virus-specific T-cells. J. Gen Virol. 92(Pt 10), 2339-2349. doi: 10.1099/vir.0.033076-0

Hirano, D., Ohshima, N., Kubota-Koketsu, R., Yamasaki, A., Kurosawa, G., Okuno, Y., et al. (2018). Three types of broadly reacting antibodies against influenza B viruses induced by vaccination with seasonal influenza viruses. J. Immunol. Res. 2018:7251793. doi: 10.1155/2018/7251793

Hoft, D. F., Babusis, E., Worku, S., Spencer, C. T., Lottenbach, K., Truscott, S. M., et al. (2011). Live and inactivated influenza vaccines induce similar humoral responses, but only live vaccines induce diverse T-cell responses in young children. J. Infect. Dis. 204, 845-853. doi: 10.1093/infdis/jir436

Huber, V. C., Lynch, J. M., Bucher, D. J., Le, J., and Metzger, D. W. (2001). Fc receptor-mediated phagocytosis makes a significant contribution to clearance of influenza virus infections. J. Immunol. 166, 7381-7388. doi: 10.4049/jimmunol.166.12.7381

Iba, Y., Fujii, Y., Ohshima, N., Sumida, T., Kubota-Koketsu, R., Ikeda, M., et al. (2014). Conserved neutralizing epitope at globular head of hemagglutinin in H3N2 influenza viruses. J. Virol. 88, 7130-7144. doi: 10.1128/JVI.00420-14

Ibanez, L. I., Roose, K., De Filette, M., Schotsaert, M., De Sloovere, J., Roels, S., et al. (2013). M2e-displaying virus-like particles with associated RNA promote T helper 1 type adaptive immunity against influenza A. PLOS ONE 8:e59081. doi: 10.1371/journal.pone.0059081

Impagliazzo, A., Milder, F., Kuipers, H., Wagner, M. V., Zhu, X., Hoffman, R. M., et al. (2015). A stable trimeric influenza hemagglutinin stem as a broadly protective immunogen. Science 349, 1301-1306. doi: 10.1126/science.aac7263

Isakova-Sivak, I., Korenkov, D., Smolonogina, T., Kotomina, T., Donina, S., Matyushenko, V., et al. (2018). Broadly protective anti-hemagglutinin stalk antibodies induced by live attenuated influenza vaccine expressing chimeric hemagglutinin. Virology 518, 313-323. doi: 10.1016/j.virol.2018.03.013

Jameson, J., Cruz, J., and Ennis, F. A. (1998). Human cytotoxic T-lymphocyte repertoire to influenza A viruses. J. Virol. 72, 8682-8689.

Jang, Y. H., Byun, Y. H., Lee, D. H., Lee, K. H., Lee, Y. J., Lee, Y. H., et al. (2013a). Cold-adapted X-31 live attenuated 2009 pandemic H1N1 influenza vaccine elicits protective immune responses in mice and ferrets. Vaccine 31, 1320-1327. doi: $10.1016 /$ j.vaccine.2012.12.072

Jang, Y. H., Byun, Y. H., Lee, K. H., Park, E. S., Lee, Y. H., Lee, Y. J., et al. (2013b). Host defense mechanism-based rational design of live vaccine. PLoS ONE 8:e75043. doi: 10.1371/journal.pone.0075043

Jang, Y. H., Byun, Y. H., Lee, Y. J., Lee, Y. H., Lee, K. H., and Seong, B. L. (2012), Cold-adapted pandemic 2009 H1N1 influenza virus live vaccine elicits crossreactive immune responses against seasonal and $\mathrm{H} 5$ influenza A viruses. J. Virol. 86, 5953-5958. doi: 10.1128/JVI.07149-11

Jang, Y. H., Jung, E. J., Byun, Y. H., Lee, K. H., Lee, E. Y., Lee, Y. J., et al. (2013c). Immunogenicity and protective efficacy of cold-adapted X-31 live 
attenuated pre-pandemic H5N1 influenza vaccines. Vaccine 31, 3339-3346. doi: 10.1016/j.vaccine.2013.05.080

Jang, Y. H., Jung, E. J., Lee, K. H., Byun, Y. H., Yang, S. W., and Seong, B. L. (2016). Genetic analysis of attenuation markers of cold-adapted X-31 influenza live vaccine donor strain. Vaccine 34, 1343-1349. doi: 10.1016/j.vaccine.2016.01.053

Jang, Y. H., Kim, J. Y., Byun, Y. H., Son, A., Lee, J. Y., Lee, Y. J., et al. (2018). Pan-influenza A protection by prime-boost vaccination with cold-adapted live-attenuated influenza vaccine in a mouse model. Front. Immunol. 9:116. doi: 10.3389/fimmu.2018.00116

Jang, Y. H., Lee, E. Y., Byun, Y. H., Jung, E. J., Lee, Y. J., Lee, Y. H., et al. (2014). Protective efficacy in mice of monovalent and trivalent live attenuated influenza vaccines in the background of cold-adapted $\mathrm{A} / \mathrm{X}-31$ and $\mathrm{B} /$ Lee/40 donor strains. Vaccine 32, 535-543. doi: 10.1016/j.vaccine.2013.12.002

Jang, Y. H., and Seong, B. L. (2013a). Cross-protective immune responses elicited by live attenuated influenza vaccines. Yonsei Med. J. 54, 271-282. doi: $10.3349 / y m j .2013 .54 .2 .271$

Jang, Y. H., and Seong, B. L. (2013b). Toward a universal influenza vaccine: from the perspective of protective efficacy. Clin. Exp. Vaccine Res. 2, 71-73. doi: $10.7774 /$ cevr.2013.2.2.71

Jang, Y. H., and Seong, B. L. (2014). Options and obstacles for designing a universal influenza vaccine. Viruses 6, 3159-3180. doi: 10.3390/v6083159

Janjua, N. Z., Skowronski, D. M., Hottes, T. S., Osei, W., Adams, E., Petric, M., et al. (2010). Seasonal influenza vaccine and increased risk of pandemic A/H1N1related illness: first detection of the association in British Columbia, Canada. Clin. Infect. Dis. 51, 1017-1027. doi: 10.1086/656586

Jefferson, T., Di Pietrantonj, C., Rivetti, A., Bawazeer, G. A., AlAnsary, L. A., and Ferroni, E. (2010). Vaccines for preventing influenza in healthy adults. Cochrane Database Syst. Rev. 7:Cd001269. doi: 10.1002/14651858.CD001269.pub4

Jefferson, T., Rivetti, A., Harnden, A., Di Pietrantonj, C., and Demicheli, V. (2008). Vaccines for preventing influenza in healthy children. Cochrane Database Syst. Rev. 16:Cd004879. doi: 10.1002/14651858.CD004879.pub3

Jegaskanda, S., Co, M. D. T., Cruz, J., Subbarao, K., Ennis, F. A., and Terajima, M. (2017a). Induction of H7N9-cross-reactive antibody-dependent cellular cytotoxicity antibodies by human seasonal influenza A viruses that are directed toward the nucleoprotein. J. Infect. Dis. 215, 818-823. doi: 10.1093/infdis/jiw629

Jegaskanda, S., Vandenberg, K., Laurie, K. L., Loh, L., Kramski, M., Winnall, W. R., et al. (2014). Cross-reactive influenza-specific antibody-dependent cellular cytotoxicity in intravenous immunoglobulin as a potential therapeutic against emerging influenza viruses. J. Infect. Dis. 210, 1811-1822. doi: 10.1093/infdis/jiu334

Jegaskanda, S., Vanderven, H. A., Wheatley, A. K., and Kent, S. J. (2017b). Fc or not Fc; that is the question: antibody Fc-receptor interactions are key to universal influenza vaccine design. Hum. Vaccin Immunother. 13, 1-9. doi: 10.1080/21645515.2017.1290018

Jegerlehner, A., Schmitz, N., Storni, T., and Bachmann, M. F. (2004). Influenza A vaccine based on the extracellular domain of M2: weak protection mediated via antibody-dependent NK cell activity. J. Immunol. 172, 5598-5605. doi: 10.4049/jimmunol.172.9.5598

Job, E. R., Ysenbaert, T., Smet, A., Christopoulou, I., Strugnell, T., Oloo, E. O., et al. (2018). Broadened immunity against influenza by vaccination with computationally designed influenza virus N1 neuraminidase constructs. NPJ Vaccines 3:55. doi: 10.1038/s41541-018-0093-1

Johansson, B. E., and Kilbourne, E. D. (1993). Dissociation of influenza virus hemagglutinin and neuraminidase eliminates their intravirionic antigenic competition. J. Virol. 67, 5721-5723.

Johansson, B. E., and Kilbourne, E. D. (1996). Immunization with dissociated neuraminidase, matrix, and nucleoproteins from influenza A virus eliminates cognate help and antigenic competition. Virology 225, 136-144. doi: 10.1006/viro.1996.0581

Johansson, B. E., Moran, T. M., and Kilbourne, E. D. (1987). Antigen-presenting $\mathrm{B}$ cells and helper $\mathrm{T}$ cells cooperatively mediate intravirionic antigenic competition between influenza A virus surface glycoproteins. Proc. Natl. Acad. Sci. U.S.A. 84, 6869-6873. doi: 10.1073/pnas.84.19.6869

Keshavarz, M., Namdari, H., Arjeini, Y., Mirzaei, H., Salimi, V., Sadeghi, A., et al. (2019). Induction of protective immune response to intranasal administration of influenza virus-like particles in a mouse model. J. Cell Physiol. 226, 1110-1117. doi: 10.1002/jcp.28339

Khurana, S. (2018). Development and regulation of novel influenza virus vaccines: a United States young scientist perspective. Vaccines 6:24. doi: $10.3390 /$ vaccines6020024

Khurana, S., Loving, C. L., Manischewitz, J., King, L. R., Gauger, P. C., Henningson, J., et al. (2013). Vaccine-induced anti-HA2 antibodies promote virus fusion and enhance influenza virus respiratory disease. Sci. Transl. Med. 5:200ra114. doi: 10.1126/scitranslmed.3006366

Kilbourne, E. D. (2006). Influenza pandemics of the 20th century. Emerg Infect. Dis. 12, 9-14. doi: 10.3201/eid1201.051254

Kim, H., Webster, R. G., and Webby, R. J. (2018a). Influenza virus: dealing with a drifting and shifting pathogen. Viral. Immunol. 31, 174-183. doi: 10.1089/vim.2017.0141

Kim, K. H., Lee, Y. T., Park, S., Jung, Y. J., Lee, Y., Ko, E. J., et al. (2019). Neuraminidase expressing virus-like particle vaccine provides effective cross protection against influenza virus. Virology 535, 179-188. doi: 10.1016/j.virol.2019.07.008

Kim, M. C., Lee, J. W., Choi, H. J., Lee, Y. N., Hwang, H. S., Lee, J., et al. (2015). Microneedle patch delivery to the skin of virus-like particles containing heterologous M2e extracellular domains of influenza virus induces broad heterosubtypic cross-protection. J. Control Release 210, 208-216. doi: 10.1016/j.jconrel.2015.05.278

Kim, Y. J., Kim, K. H., Ko, E. J., Kim, M. C., Lee, Y. N., Jung, Y. J., et al. (2018b). Complement C3 plays a key role in inducing humoral and cellular immune responses to influenza virus strain-specific hemagglutinin-based or crossprotective M2 extracellular domain-based vaccination. J. Virol. 92:e00969-18. doi: 10.1128/JVI.00969-18

Kim, Y. J., Lee, Y. T., Kim, M. C., Lee, Y. N., Kim, K. H., Ko, E. J., et al. (2017). Cross-protective efficacy of influenza virus M2e containing virus-like particles is superior to hemagglutinin vaccines and variable depending on the genetic backgrounds of mice. Front. Immunol. 8:1730. doi: 10.3389/fimmu.2017. 01730

Kirkpatrick, E., Qiu, X., Wilson, P. C., Bahl, J., and Krammer, F. (2018). The influenza virus hemagglutinin head evolves faster than the stalk domain. Sci. Rep. 8:10432. doi: 10.1038/s41598-018-28706-1

Koday, M. T., Leonard, J. A., Munson, P., Forero, A., Koday, M., Bratt, D. L., et al. (2017). Multigenic DNA vaccine induces protective cross-reactive T cell responses against heterologous influenza virus in nonhuman primates. PLoS ONE 12:e0189780. doi: 10.1371/journal.pone.0189780

Kosik, I., Angeletti, D., Gibbs, J. S., Angel, M., Takeda, K., Kosikova, M., et al. (2019). Neuraminidase inhibition contributes to influenza A virus neutralization by anti-hemagglutinin stem antibodies. J. Exp. Med. 216, 304-316. doi: 10.1084/jem.20181624

Koutsakos, M., Illing, P. T., Nguyen, T. H. O., Mifsud, N. A., Crawford, J. C., Rizzetto, S., et al. (2019). Human CD8(+) T cell cross-reactivity across influenza A, B and C viruses. Nat. Immunol. 20, 613-625. doi: 10.1038/s41590-019-0320-6

Krammer, F. (2019). The human antibody response to influenza A virus infection and vaccination. Nat. Rev. Immunol. 19, 383-397. doi: 10.1038/s41577-019-0143-6

Krammer, F., Fouchier, R. A. M., Eichelberger, M. C., Webby, R. J., ShawSaliba, K., Wan, H., et al. (2018a). NAction! How can neuraminidase-based immunity contribute to better influenza virus vaccines? MBio 9:e02332-e02317. doi: 10.1128/mBio.02332-17

Krammer, F., Garcia-Sastre, A., and Palese, P. (2018b). Is it possible to develop a "universal" influenza virus vaccine? Potential target antigens and critical aspects for a universal influenza vaccine. Cold Spring Harb Perspect. Biol. 10:a028845. doi: 10.1101/cshperspect.a028845

Krammer, F., Hai, R., Yondola, M., Tan, G. S., Leyva-Grado, V. H., Ryder, A. B., et al. (2014). Assessment of influenza virus hemagglutinin stalk-based immunity in ferrets. J. Virol. 88, 3432-3442. doi: 10.1128/JVI.03004-13

Krammer, F., and Palese, P. (2013). Influenza virus hemagglutinin stalk-based antibodies and vaccines. Curr. Opin. Virol. 3, 521-530. doi: 10.1016/j.coviro.2013.07.007

Krammer, F., and Palese, P. (2015). Advances in the development of influenza virus vaccines. Nat. Rev. Drug Discov. 14, 167-182. doi: 10.1038/nrd4529 
Krammer, F., Pica, N., Hai, R., Margine, I., and Palese, P. (2013). Chimeric hemagglutinin influenza virus vaccine constructs elicit broadly protective stalkspecific antibodies. J. Virol. 87, 6542-6550. doi: 10.1128/JVI.00641-13

Krause, J. C., Tsibane, T., Tumpey, T. M., Huffman, C. J., Albrecht, R., Blum, D. L., et al. (2012). Human monoclonal antibodies to pandemic 1957 H2N2 and pandemic 1968 H3N2 influenza viruses. J. Virol. 86, 6334-6340. doi: 10.1128/JVI.07158-11

Krause, J. C., Tsibane, T., Tumpey, T. M., Huffman, C. J., Basler, C. F., and Crowe, J. E. Jr. (2011). A broadly neutralizing human monoclonal antibody that recognizes a conserved, novel epitope on the globular head of the influenza H1N1 virus hemagglutinin. J. Virol. 85, 10905-10908. doi: 10.1128/JVI.00700-11

Kreijtz, J. H., Bodewes, R., van Amerongen, G., Kuiken, T., Fouchier, R. A., Osterhaus, A. D., et al. (2007). Primary influenza A virus infection induces cross-protective immunity against a lethal infection with a heterosubtypic virus strain in mice. Vaccine 25, 612-620. doi: 10.1016/j.vaccine.2006.08.036

Kreijtz, J. H., Bodewes, R., van den Brand, J. M., de Mutsert, G., Baas, C., van Amerongen, G., et al. (2009). Infection of mice with a human influenza A/H3N2 virus induces protective immunity against lethal infection with influenza A/H5N1 virus. Vaccine 27, 4983-4989. doi: 10.1016/j.vaccine.2009.05.079

Kreijtz, J. H., de Mutsert, G., van Baalen, C. A., Fouchier, R. A., Osterhaus, A. D., and Rimmelzwaan, G. F. (2008). Cross-recognition of avian H5N1 influenza virus by human cytotoxic T-lymphocyte populations directed to human influenza A virus. J. Virol. 82, 5161-5166. doi: 10.1128/JVI.02694-07

Leclerc, D., Rivest, M., Babin, C., Lopez-Macias, C., and Savard, P. (2013). A novel M2e based flu vaccine formulation for dogs. PLoS ONE 8:e77084. doi: 10.1371/journal.pone.0077084

Ledgerwood, J. E., Zephir, K., Hu, Z., Wei, C. J., Chang, L., Enama, M. E., et al. (2013). Prime-boost interval matters: a randomized phase 1 study to identify the minimum interval necessary to observe the H5 DNA influenza vaccine priming effect. J. Infect. Dis. 208, 418-422. doi: 10.1093/infdis/jit180

Lee, J., Boutz, D. R., Chromikova, V., Joyce, M. G., Vollmers, C., Leung, K., et al. (2016). Molecular-level analysis of the serum antibody repertoire in young adults before and after seasonal influenza vaccination. Nat. Med. 22, 1456-1464. doi: $10.1038 / \mathrm{nm} .4224$

Lee, K. H., and Seong, B. L. (1998). The position 4 nucleotide at the 3 ' end of the influenza virus neuraminidase vRNA is involved in temporal regulation of transcription and replication of neuraminidase RNAs and affects the repertoire of influenza virus surface antigens. J. Gen Virol. 79 (Pt 8), 1923-1934. doi: 10.1099/0022-1317-79-8-1923

Lee, L. Y., Ha do, L. A., Simmons, C., de Jong, M. D., Chau, N. V., Schumacher, R., et al. (2008). Memory $T$ cells established by seasonal human influenza A infection cross-react with avian influenza A (H5N1) in healthy individuals. J. Clin. Invest. 118, 3478-3490. doi: 10.1172/JCI32460

Lee, L. Y. Y., Izzard, L., and Hurt, A. C. (2018a). A review of DNA vaccines against influenza. Front. Immunol. 9:1568. doi: 10.3389/fimmu.2018.01568

Lee, Y. J., Yu, J. E., Kim, P., Lee, J. Y., Cheong, Y. C., Lee, Y. J., et al. (2018b). Eliciting unnatural immune responses by activating cryptic epitopes in viral antigens. FASEB J. 32, 4658-4669. doi: 10.1096/fj.201701024RRR

Lee, Y. N., Kim, M. C., Lee, Y. T., Kim, Y. J., and Kang, S. M. (2015). Mechanisms of cross-protection by influenza virus M2-based vaccines. Immune Netw. 15, 213-221. doi: 10.4110/in.2015.15.5.213

Lee, Y. N., Lee, Y. T., Kim, M. C., Hwang, H. S., Lee, J. S., Kim, K. H., et al. (2014). Fc receptor is not required for inducing antibodies but plays a critical role in conferring protection after influenza M2 vaccination. Immunology 143, 300-309. doi: 10.1111/imm.12310

Lin, S. C., Lin, Y. F., Chong, P., and Wu, S. C. (2012). Broader neutralizing antibodies against $\mathrm{H} 5 \mathrm{~N} 1$ viruses using prime-boost immunization of hyperglycosylated hemagglutinin DNA and virus-like particles. PLoS ONE 7:e39075. doi: 10.1371/journal.pone.0039075

Lin, S. C., Liu, W. C., Jan, J. T., and Wu, S. C. (2014). Glycan masking of hemagglutinin for adenovirus vector and recombinant protein immunizations elicits broadly neutralizing antibodies against $\mathrm{H} 5 \mathrm{~N} 1$ avian influenza viruses. PLoS ONE 9:e92822. doi: 10.1371/journal.pone.0092822

Lin, Y. P., Gregory, V., Collins, P., Kloess, J., Wharton, S., Cattle, N., et al. (2010). Neuraminidase receptor binding variants of human influenza $\mathrm{A}(\mathrm{H} 3 \mathrm{~N} 2)$ viruses resulting from substitution of aspartic acid 151 in the catalytic site: a role in virus attachment? J. Virol. 84, 6769-6781. doi: 10.1128/JVI.00458-10
Liu, W.-C., Nachbagauer, R., Stadlbauer, D., Solórzano, A., Berlanda-Scorza, F., García-Sastre, A., et al. (2019a). Sequential immunization with live-attenuated chimeric hemagglutinin-based vaccines confers heterosubtypic immunity against influenza A viruses in a preclinical ferret model. Front. Immunol. 10:756. doi: 10.3389/fimmu.2019.00756

Liu, W. C., Lin, C. Y., Tsou, Y. T., Jan, J. T., and Wu, S. C. (2015). Crossreactive neuraminidase-inhibiting antibodies elicited by immunization with recombinant neuraminidase proteins of $\mathrm{H} 5 \mathrm{~N} 1$ and pandemic $\mathrm{H} 1 \mathrm{~N} 1$ influenza A viruses. J. Virol. 89, 7224-7234. doi: 10.1128/JVI.00585-15

Liu, Y., Tan, H. X., Koutsakos, M., Jegaskanda, S., Esterbauer, R., Tilmanis, D., et al. (2019b). Cross-lineage protection by human antibodies binding the influenza B hemagglutinin. Nat. Commun. 10:324. doi: 10.1038/s41467-018-08165-y

Lowen, A. C. (2017). Constraints, drivers, and implications of influenza A virus reassortment. Annu. Rev. Virol. 4, 105-121. doi: 10.1146/annurev-virology-101416-041726

Lu, Y., Welsh, J. P., and Swartz, J. R. (2014). Production and stabilization of the trimeric influenza hemagglutinin stem domain for potentially broadly protective influenza vaccines. Proc. Natl. Acad. Sci. U.S.A. 111, 125-130. doi: 10.1073/pnas.1308701110

Mallajosyula, V. V., Citron, M., Ferrara, F., Lu, X., Callahan, C., Heidecker, G. J., et al. (2014). Influenza hemagglutinin stem-fragment immunogen elicits broadly neutralizing antibodies and confers heterologous protection. Proc. Natl. Acad. Sci. U.S.A. 111, E2514-2523. doi: 10.1073/pnas.14027 66111

Margine, I., Krammer, F., Hai, R., Heaton, N. S., Tan, G. S., Andrews, S. A., et al. (2013). Hemagglutinin stalk-based universal vaccine constructs protect against group 2 influenza A viruses. J. Virol. 87, 10435-10446. doi: 10.1128/JVI.01715-13

McMahon, M., Kirkpatrick, E., Stadlbauer, D., Strohmeier, S., Bouvier, N. M., and Krammer, F. (2019). Mucosal immunity against neuraminidase prevents influenza B virus transmission in Guinea Pigs. MBio 10:e00560-19. doi: 10.1128/mBio.00560-19

Memoli, M. J., Shaw, P. A., Han, A., Czajkowski, L., Reed, S., Athota, R., et al. (2016). Evaluation of antihemagglutinin and antineuraminidase antibodies as correlates of protection in an influenza $\mathrm{A} / \mathrm{H} 1 \mathrm{~N} 1$ virus healthy human challenge model. MBio 7:e00417-e00416. doi: 10.1128/mBio.00417-16

Meseda, C. A., Atukorale, V., Soto, J., Eichelberger, M. C., Gao, J., Wang, W., et al. (2018). Immunogenicity and protection against influenza $\mathrm{H} 7 \mathrm{~N} 3$ in mice by modified vaccinia virus Ankara vectors expressing influenza virus hemagglutinin or neuraminidase. Sci. Rep. 8:5364. doi: 10.1038/s41598-018-23712-9

Mogling, R., Richard, M. J., Vliet, S. V., Beek, R. V., Schrauwen, E. J. A., Spronken, M. I., et al. (2017). Neuraminidase-mediated haemagglutination of recent human influenza $\mathrm{A}(\mathrm{H} 3 \mathrm{~N} 2)$ viruses is determined by arginine 150 flanking the neuraminidase catalytic site. J. Gen Virol. 98, 1274-1281. doi: 10.1099/jgv.0.000809

Mohn, K. G., Bredholt, G., Brokstad, K. A., Pathirana, R. D., Aarstad, H. J., Tondel, C., et al. (2015). Longevity of B-cell and T-cell responses after live attenuated influenza vaccination in children. J. Infect. Dis. 211, 1541-1549. doi: 10.1093/infdis/jiu654

Mohn, K. G., Smith, I., Sjursen, H., and Cox, R. J. (2018). Immune responses after live attenuated influenza vaccination. Hum. Vaccin Immunother. 14, 571-578. doi: 10.1080/21645515.2017.1377376

Mohn, K. G. I., Zhou, F., Brokstad, K. A., Sridhar, S., and Cox, R. J. (2017). Boosting of cross-reactive and protection-associated $\mathrm{T}$ cells in children after live attenuated influenza vaccination. J. Infect. Dis. 215, 1527-1535. doi: 10.1093/infdis/jix165

Monsalvo, A. C., Batalle, J. P., Lopez, M. F., Krause, J. C., Klemenc, J., Hernandez, J. Z., et al. (2011). Severe pandemic $2009 \mathrm{H} 1 \mathrm{~N} 1$ influenza disease due to pathogenic immune complexes. Nat. Med. 17, 195-199. doi: 10.1038/nm.2262

Monto, A. S., and Kendal, A. P. (1973). Effect of neuraminidase antibody on Hong Kong influenza. Lancet 1, 623-625. doi: 10.1016/S0140-6736(73)92196-X

Monto, A. S., Petrie, J. G., Cross, R. T., Johnson, E., Liu, M., Zhong, W., et al. (2015). Antibody to influenza virus neuraminidase: an independent correlate of protection. J. Infect. Dis. 212, 1191-1199. doi: 10.1093/infdis/jiv195

Mozdzanowska, K., Feng, J., Eid, M., Kragol, G., Cudic, M., Otvos, L. Jr., et al. (2003). Induction of influenza type A virus-specific resistance by immunization of mice with a synthetic multiple antigenic peptide vaccine 
that contains ectodomains of matrix protein 2. Vaccine 21, 2616-2626. doi: 10.1016/S0264-410X(03)00040-9

Murphy, B. R., Kasel, J. A., and Chanock, R. M. (1972). Association of serum antineuraminidase antibody with resistance to influenza in man. N. Engl. J. Med. 286, 1329-1332. doi: 10.1056/NEJM197206222862502

Music, N., Reber, A. J., Kim, M. C., York, I. A., and Kang, S. M. (2016). Supplementation of H1N1pdm09 split vaccine with heterologous tandem repeat M2e5x virus-like particles confers improved cross-protection in ferrets. Vaccine 34, 466-473. doi: 10.1016/j.vaccine.2015.12.023

Nachbagauer, R., Krammer, F., and Albrecht, R. A. (2018). A live-attenuated prime, inactivated boost vaccination strategy with chimeric hemagglutininbased universal influenza virus vaccines provides protection in ferrets: a confirmatory study. Vaccines 6:47. doi: 10.3390/vaccines6030047

Nachbagauer, R., Liu, W. C., Choi, A., Wohlbold, T. J., Atlas, T., Rajendran, M., et al. (2017). A universal influenza virus vaccine candidate confers protection against pandemic H1N1 infection in preclinical ferret studies. NPJ Vaccines 2:26. doi: 10.1038/s41541-017-0026-4

Neirynck, S., Deroo, T., Saelens, X., Vanlandschoot, P., Jou, W. M., and Fiers, W. (1999). A universal influenza A vaccine based on the extracellular domain of the M2 protein. Nat. Med. 5, 1157-1163. doi: 10.1038/13484

Ng, S., Nachbagauer, R., Balmaseda, A., Stadlbauer, D., Ojeda, S., Patel, M., et al. (2019). Novel correlates of protection against pandemic H1N1 influenza A virus infection. Nat. Med. 25, 962-967. doi: 10.1038/s41591-019-0463-x

Oh, H. L., Akerstrom, S., Shen, S., Bereczky, S., Karlberg, H., Klingstrom, J., et al. (2010). An antibody against a novel and conserved epitope in the hemagglutinin 1 subunit neutralizes numerous $\mathrm{H} 5 \mathrm{~N} 1$ influenza viruses. J. Virol. 84, 8275-8286. doi: 10.1128/JVI.02593-09

Ohmit, S. E., Petrie, J. G., Cross, R. T., Johnson, E., and Monto, A. S. (2011). Influenza hemagglutination-inhibition antibody titer as a correlate of vaccineinduced protection. J. Infect. Dis. 204, 1879-1885. doi: 10.1093/infdis/jir661

Pardi, N., Hogan, M. J., Porter, F. W., and Weissman, D. (2018a). mRNA vaccines - a new era in vaccinology. Nat. Rev. Drug Discov. 17, 261-279. doi: $10.1038 / \mathrm{nrd} .2017 .243$

Pardi, N., Parkhouse, K., Kirkpatrick, E., McMahon, M., Zost, S. J., Mui, B. L., et al. (2018b). Nucleoside-modified mRNA immunization elicits influenza virus hemagglutinin stalk-specific antibodies. Nat. Commun. 9:3361. doi: 10.1038/s41467-018-05482-0

Park, J. K., Han, A., Czajkowski, L., Reed, S., Athota, R., Bristol, T., et al. (2018). Evaluation of preexisting anti-hemagglutinin stalk antibody as a correlate of protection in a healthy volunteer challenge with influenza A/H1N1pdm Virus. MBio 9:e02284-17. doi: 10.1128/mBio.02284-17

Paul, S. S., Mok, C. K., Mak, T. M., Ng, O. W., Aboagye, J. O., Wohlbold, T. J., et al. (2017). A cross-clade H5N1 influenza A virus neutralizing monoclonal antibody binds to a novel epitope within the vestigial esterase domain of hemagglutinin. Antiviral Res. 144, 299-310. doi: 10.1016/j.antiviral.2017. 06.012

Paules, C., and Subbarao, K. (2017). Influenza. Lancet 390, 697-708. doi: 10.1016/S0140-6736(17)30129-0

Paules, C. I., Marston, H. D., Eisinger, R. W., Baltimore, D., and Fauci, A. S. (2017). The pathway to a universal influenza vaccine. Immunity 47, 599-603. doi: 10.1016/j.immuni.2017.09.007

Peiris, J. S., Hui, K. P., and Yen, H. L. (2010). Host response to influenza virus: protection versus immunopathology. Curr. Opin. Immunol. 22, 475-481. doi: $10.1016 /$ j.coi.2010.06.003

Pendzialek, J., Roose, K., Smet, A., Schepens, B., Kufer, P., Raum, T., et al. (2017). Bispecific $\mathrm{T}$ cell engaging antibody constructs targeting a universally conserved part of the viral M2 ectodomain cure and prevent influenza A virus infection. Antiviral Res. 141, 155-164. doi: 10.1016/j.antiviral.2017.02.016

Perez, J. T., Pham, A. M., Lorini, M. H., Chua, M. A., Steel, J., and tenOever, B. R. (2009). MicroRNA-mediated species-specific attenuation of influenza A virus. Nat. Biotechnol. 27, 572-576. doi: 10.1038/nbt.1542

Petsch, B., Schnee, M., Vogel, A. B., Lange, E., Hoffmann, B., Voss, D., et al. (2012). Protective efficacy of in vitro synthesized, specific mRNA vaccines against influenza A virus infection. Nat. Biotechnol. 30, 1210-1216. doi: $10.1038 /$ nbt. 2436

Petukhova, N. V., Gasanova, T. V., Stepanova, L. A., Rusova, O. A., Potapchuk, M. V., Korotkov, A. V., et al. (2013). Immunogenicity and protective efficacy of candidate universal influenza A nanovaccines produced in plants by Tobacco mosaic virus-based vectors. Curr. Pharm. Des. 19, 5587-5600. doi: 10.2174/13816128113199990337

Piepenbrink, M. S., Nogales, A., Basu, M., Fucile, C. F., Liesveld, J. L., Keefer, M. C., et al. (2019). Broad and protective influenza B virus neuraminidase antibodies in humans after vaccination and their clonal persistence as plasma cells. MBio 10:e00066-19. doi: 10.1128/mBio.00066-19

Pinto, L. H., Holsinger, L. J., and Lamb, R. A. (1992). Influenza virus M2 protein has ion channel activity. Cell 69, 517-528. doi: 10.1016/0092-8674(92)90452-I

Porter, K. R., and Raviprakash, K. (2017). DNA vaccine delivery and improved immunogenicity. Curr. Issues Mol. Biol. 22, 129-138. doi: 10.21775/cimb.022.129

Powell, T. J., Peng, Y., Berthoud, T. K., Blais, M. E., Lillie, P. J., Hill, A. V., et al. (2013). Examination of influenza specific T cell responses after influenza virus challenge in individuals vaccinated with MVA-NP+M1 vaccine. PLoS ONE 8:e62778. doi: 10.1371/journal.pone.0062778

Powell, T. J., Silk, J. D., Sharps, J., Fodor, E., and Townsend, A. R. (2012). Pseudotyped influenza A virus as a vaccine for the induction of heterotypic immunity. J. Virol. 86, 13397-13406. doi: 10.1128/JVI.01820-12

Price, G. E., Soboleski, M. R., Lo, C. Y., Misplon, J. A., Pappas, C., Houser, K. V., et al. (2009). Vaccination focusing immunity on conserved antigens protects mice and ferrets against virulent $\mathrm{H} 1 \mathrm{~N} 1$ and $\mathrm{H} 5 \mathrm{~N} 1$ influenza A viruses. Vaccine 27, 6512-6521. doi: 10.1016/j.vaccine.2009.08.053

Rajao, D. S., Chen, H., Perez, D. R., Sandbulte, M. R., Gauger, P. C., Loving, C. L., et al. (2016). Vaccine-associated enhanced respiratory disease is influenced by haemagglutinin and neuraminidase in whole inactivated influenza virus vaccines. J. Gen. Virol. 97, 1489-1499. doi: 10.1099/jgv.0.000468

Rajao, D. S., Loving, C. L., Gauger, P. C., Kitikoon, P., and Vincent, A. L. (2014). Influenza A virus hemagglutinin protein subunit vaccine elicits vaccine-associated enhanced respiratory disease in pigs. Vaccine 32, 5170-5176. doi: 10.1016/j.vaccine.2014.07.059

Ravin, N. V., Blokhina, E. A., Kuprianov, V. V., Stepanova, L. A., Shaldjan, A. A., Kovaleva, A. A., et al. (2015). Development of a candidate influenza vaccine based on virus-like particles displaying influenza M2e peptide into the immunodominant loop region of hepatitis B core antigen: Insertion of multiple copies of M2e increases immunogenicity and protective efficiency. Vaccine 33, 3392-3397. doi: 10.1016/j.vaccine.2015.04.066

Raymond, D. D., Bajic, G., Ferdman, J., Suphaphiphat, P., Settembre, E. C., Moody, M. A., et al. (2018). Conserved epitope on influenza-virus hemagglutinin head defined by a vaccine-induced antibody. Proc. Natl. Acad. Sci. U.S.A. 115, 168-173. doi: 10.1073/pnas.1715471115

Rekstin, A., Isakova-Sivak, I., Petukhova, G., Korenkov, D., Losev, I., Smolonogina, T., et al. (2017). Immunogenicity and cross protection in mice afforded by pandemic H1N1 live attenuated influenza vaccine containing wild-type nucleoprotein. Biomed. Res. Int. 2017:9359276. doi: 10.1155/2017/9359276

Rosendahl Huber, S. K., Camps, M. G., Jacobi, R. H., Mouthaan, J., van Dijken, H., van Beek, J., et al. (2015). Synthetic long peptide influenza vaccine containing conserved $\mathrm{T}$ and $\mathrm{B}$ cell epitopes reduces viral load in lungs of mice and ferrets. PLoS ONE 10:e0127969. doi: 10.1371/journal.pone.0127969

Sagawa, H., Ohshima, A., Kato, I., Okuno, Y., and Isegawa, Y. (1996). The immunological activity of a deletion mutant of influenza virus haemagglutinin lacking the globular region. J. Gen Virol. 77 (Pt 7), 1483-1487. doi: 10.1099/0022-1317-77-7-1483

Sakai, T., Nishimura, S. I., Naito, T., and Saito, M. (2017). Influenza A virus hemagglutinin and neuraminidase act as novel motile machinery. Sci. Rep. 7:45043. doi: 10.1038/srep45043

Sarawar, S., Hatta, Y., Watanabe, S., Dias, P., Neumann, G., Kawaoka, Y., et al. (2016). M2SR, a novel live single replication influenza virus vaccine, provides effective heterosubtypic protection in mice. Vaccine 34, 5090-5098. doi: 10.1016/j.vaccine.2016.08.061

Saunders-Hastings, P. R., and Krewski, D. (2016). Reviewing the history of pandemic influenza: understanding patterns of emergence and transmission. Pathogens 5:66. doi: 10.3390/pathogens5040066

Schulman, J. L. (1969). The role of antineuraminidase antibody in immunity to influenza virus infection. Bull World Health Organ. 41, 647-650.

Schulman, J. L., and Kilbourne, E. D. (1969). Independent variation in nature of hemagglutinin and neuraminidase antigens of influenza virus: distinctiveness of hemagglutinin antigen of Hong Kong-68 virus. Proc. Natl. Acad. Sci. U.S.A. 63, 326-333. doi: 10.1073/pnas.63.2.326 
Shen, C., Chen, J., Li, R., Zhang, M., Wang, G., Stegalkina, S., et al. (2017). A multimechanistic antibody targeting the receptor binding site potently cross-protects against influenza B viruses. Sci. Transl. Med. 9:eaam5752. doi: 10.1126/scitranslmed.aam5752

Skowronski, D. M., De Serres, G., Crowcroft, N. S., Janjua, N. Z., Boulianne, N., Hottes, T. S., et al. (2010). Association between the 2008-09 seasonal influenza vaccine and pandemic $\mathrm{H} 1 \mathrm{~N} 1$ illness during Spring-Summer 2009: four observational studies from Canada. PLoS Med. 7:e1000258. doi: 10.1371/journal.pmed.1000258

Song, B. M., Kang, H. M., Lee, E. K., Jung, S. C., Kim, M. C., Lee, Y. N., et al. (2016). Supplemented vaccination with tandem repeat M2e virus-like particles enhances protection against homologous and heterologous HPAI H5 viruses in chickens. Vaccine 34, 678-686. doi: 10.1016/j.vaccine.2015.11.074

Sridhar, S. (2016). Heterosubtypic T-cell immunity to influenza in humans: challenges for universal T-cell influenza vaccines. Front. Immunol. 7:195. doi: 10.3389/fimmu.2016.00195

Sridhar, S., Brokstad, K. A., and Cox, R. J. (2015). Influenza vaccination strategies: comparing inactivated and live attenuated influenza vaccines. Vaccines 3, 373-389. doi: 10.3390/vaccines3020373

Stech, J., Garn, H., Wegmann, M., Wagner, R., and Klenk, H. D. (2005). A new approach to an influenza live vaccine: modification of the cleavage site of hemagglutinin. Nat. Med. 11, 683-689. doi: 10.1038/nm1256

Steel, J., Lowen, A. C., Wang, T. T., Yondola, M., Gao, Q., Haye, K., et al. (2010). Influenza virus vaccine based on the conserved hemagglutinin stalk domain. MBio 1:e00018-10. doi: 10.1128/mBio.00018-10

Su, B., Wurtzer, S., Rameix-Welti, M.-A., Dwyer, D., van der Werf, S., Naffakh, N., et al. (2010). Enhancement of the influenza A hemagglutinin (HA)-mediated cell-cell fusion and virus entry by the viral neuraminidase (NA). PLoS ONE 4:e8495. doi: 10.1371/journal.pone.0008495

Subbramanian, R. A., Basha, S., Shata, M. T., Brady, R. C., and Bernstein, D. I. (2010). Pandemic and seasonal H1N1 influenza hemagglutinin-specific $\mathrm{T}$ cell responses elicited by seasonal influenza vaccination. Vaccine 28, 8258-8267. doi: 10.1016/j.vaccine.2010. 10.077

Sui, J., Hwang, W. C., Perez, S., Wei, G., Aird, D., Chen, L. M., et al. (2009). Structural and functional bases for broad-spectrum neutralization of avian and human influenza A viruses. Nat. Struct. Mol. Biol. 16, 265-273. doi: $10.1038 / \mathrm{nsmb} .1566$

Sun, W., Kirkpatrick, E., Ermler, M., Nachbagauer, R., Broecker, F., Krammer, F., et al. (2019). Development of influenza B universal vaccine candidates using the "mosaic" hemagglutinin approach. J. Virol. 93:e00333-19. doi: 10.1128/JVI.00333-19

Sun, X., Wang, Y., Dong, C., Hu, J., and Yang, L. (2015). High copy numbers and $\mathrm{N}$ terminal insertion position of influenza A M2E fused with hepatitis B core antigen enhanced immunogenicity. Biosci. Trends 9, 221-227. doi: 10.5582/bst.2015.01060

Talon, J., Salvatore, M., O’Neill, R. E., Nakaya, Y., Zheng, H., Muster, T., et al. (2000). Influenza A and B viruses expressing altered NS1 proteins: a vaccine approach. Proc. Natl. Acad. Sci. U.S.A. 97, 4309-4314. doi: 10.1073/pnas.070525997

Tan, G. S., Lee, P. S., Hoffman, R. M., Mazel-Sanchez, B., Krammer, F., Leon, P. E., et al. (2014). Characterization of a broadly neutralizing monoclonal antibody that targets the fusion domain of group 2 influenza A virus hemagglutinin. J. Virol. 88, 13580-13592. doi: 10.1128/JVI.02289-14

Tan, G. S., Leon, P. E., Albrecht, R. A., Margine, I., Hirsh, A., Bahl, J., et al. (2016). Broadly-reactive neutralizing and non-neutralizing antibodies directed against the $\mathrm{H} 7$ influenza virus hemagglutinin reveal divergent mechanisms of protection. PLoS Pathog. 12:e1005578. doi: 10.1371/journal.ppat.10 05578

Tan, J., Asthagiri Arunkumar, G., and Krammer, F. (2018). Universal influenza virus vaccines and therapeutics: where do we stand with influenza B virus? Curr. Opin. Immunol. 53, 45-50. doi: 10.1016/j.coi.2018.04.002

Terajima, M., Babon, J. A., Co, M. D., and Ennis, F. A. (2013). Cross-reactive human B cell and T cell epitopes between influenza A and B viruses. Virol. J. 10:244. doi: 10.1186/1743-422X-10-244

Terajima, M., Cruz, J., Co, M. D., Lee, J. H., Kaur, K., Wrammert, J., et al. (2011). Complement-dependent lysis of influenza a virus-infected cells by broadly cross-reactive human monoclonal antibodies. J. Virol. 85, 13463-13467. doi: 10.1128/JVI.05193-11

Tompkins, S. M., Zhao, Z. S., Lo, C. Y., Misplon, J. A., Liu, T., Ye, Z., et al. (2007). Matrix protein 2 vaccination and protection against influenza viruses, including subtype H5N1. Emerg. Infect. Dis. 13, 426-435. doi: 10.3201/eid1303.061125

Tsybalova, L. M., Stepanova, L. A., Kuprianov, V. V., Blokhina, E. A., Potapchuk, M. V., Korotkov, A. V., et al. (2015). Development of a candidate influenza vaccine based on virus-like particles displaying influenza M2e peptide into the immunodominant region of hepatitis B core antigen: broad protective efficacy of particles carrying four copies of M2e. Vaccine 33, 3398-3406. doi: 10.1016/j.vaccine.2015.04.073

Tsybalova, L. M., Stepanova, L. A., Shuklina, M. A., Mardanova, E. S., Kotlyarov, R. Y., Potapchuk, M. V., et al. (2018). Combination of M2e peptide with stalk HA epitopes of influenza A virus enhances protective properties of recombinant vaccine. PLoS ONE 13:e0201429. doi: 10.1371/journal.pone.0201429

Ui, H., Yamayoshi, S., Uraki, R., Kiso, M., Oishi, K., Murakami, S., et al. (2017) Evaluation of seasonal influenza vaccines for H1N1pdm09 and type B viruses based on a replication-incompetent PB2-KO virus. Vaccine 35, 1892-1897. doi: 10.1016/j.vaccine.2017.02.041

Ulmer, J. B., Donnelly, J. J., Parker, S. E., Rhodes, G. H., Felgner, P. L., Dwarki, V. J., et al. (1993). Heterologous protection against influenza by injection of DNA encoding a viral protein. Science 259, 1745-1749. doi: 10.1126/science.8456302

Uraki, R., Kiso, M., Iwatsuki-Horimoto, K., Fukuyama, S., Takashita, E., Ozawa, M., et al. (2013). A novel bivalent vaccine based on a PB2-knockout influenza virus protects mice from pandemic $\mathrm{H} 1 \mathrm{~N} 1$ and highly pathogenic $\mathrm{H} 5 \mathrm{~N} 1$ virus challenges. J. Virol. 87, 7874-7881. doi: 10.1128/JVI.00076-13

van de Sandt, C. E., Dou, Y., Vogelzang-van Trierum, S. E., Westgeest, K. B., Pronk, M. R., Osterhaus, A. D. M. E., et al. (2015). Influenza B virus-specific CD8+ T-lymphocytes strongly cross-react with viruses of the opposing influenza B lineage. J. Gen Virol. 96, 2061-2073. doi: 10.1099/vir.0.000156

van de Sandt, C. E., Kreijtz, J. H., de Mutsert, G., Geelhoed-Mieras, M. M., Hillaire, M. L., Vogelzang-van Trierum, S. E., et al. (2014). Human cytotoxic T lymphocytes directed to seasonal influenza A viruses cross-react with the newly emerging H7N9 virus. J. Virol. 88, 1684-1693. doi: 10.1128/JVI.02843-13

Victor, S. T., Watanabe, S., Katsura, H., Ozawa, M., and Kawaoka, Y. (2012). A replication-incompetent $\mathrm{PB} 2-$ knockout influenza A virus vaccine vector. $J$. Virol. 86, 4123-4128. doi: 10.1128/JVI.06232-11

Vigil, A., Estelles, A., Kauvar, L. M., Johnson, S. K., Tripp, R. A., and Wittekind, M. (2018). Native human monoclonal antibodies with potent crosslineage neutralization of influenza B viruses. Antimicrob. Agents Chemother. 62:e02269-e02217. doi: 10.1128/AAC.02269-17

Walz, L., Kays, S. K., Zimmer, G., and von Messling, V. (2018). Neuraminidaseinhibiting antibody titers correlate with protection from heterologous influenza virus strains of the same neuraminidase subtype. J. Virol. 92:e01006-e01018. doi: 10.1128/JVI.01006-18

Wan, H., Gao, J., Xu, K., Chen, H., Couzens, L. K., Rivers, K. H., et al. (2013). Molecular basis for broad neuraminidase immunity: conserved epitopes in seasonal and pandemic $\mathrm{H} 1 \mathrm{~N} 1$ as well as $\mathrm{H} 5 \mathrm{~N} 1$ influenza viruses. J. Virol. 87, 9290-9300. doi: 10.1128/JVI.01203-13

Wang, R., Song, A., Levin, J., Dennis, D., Zhang, N. J., Yoshida, H., et al. (2008). Therapeutic potential of a fully human monoclonal antibody against influenza A virus M2 protein. Antiviral Res. 80, 168-177. doi: 10.1016/j.antiviral.2008.06.002

Wang, S., Ren, H., Jiang, W., Chen, H., Hu, H., Chen, Z., et al. (2017). Divergent requirement of $\mathrm{Fc}-\mathrm{Fc} \gamma$ receptor interactions for in vivo protection against influenza viruses by two pan-H5 hemagglutinin antibodies. J. Virol. 91, e02065e02016. doi: 10.1128/JVI.02065-16

Wang, W., Li, R., Deng, Y., Lu, N., Chen, H., Meng, X., et al. (2015). Protective efficacy of the conserved NP, PB1, and M1 proteins as immunogens in DNAand vaccinia virus-based universal influenza $\mathrm{A}$ virus vaccines in mice. Clin. Vaccine Immunol. 22, 618-630. doi: 10.1128/CVI.00091-15

Wang, Y., Deng, L., Kang, S. M., and Wang, B. Z. (2018a). Universal influenza vaccines: from viruses to nanoparticles. Exp. Rev. Vaccines 17, 967-976. doi: 10.1080/14760584.2018.1541408

Wang, Z., Zhu, L., Nguyen, T. H. O., Wan, Y., Sant, S., Quiñones-Parra, S. M., et al. (2018b). Clonally diverse CD38+HLA-DR+CD8+ T cells persist during fatal H7N9 disease. Nat. Commun. 9:824. doi: 10.1038/s41467-018-03243-7 
Weaver, E. A., Rubrum, A. M., Webby, R. J., and Barry, M. A. (2011). Protection against divergent influenza $\mathrm{H} 1 \mathrm{~N} 1$ virus by a centralized influenza hemagglutinin. PLoS ONE 6:e18314. doi: 10.1371/journal.pone.0018314

Whittle, J. R., Zhang, R., Khurana, S., King, L. R., Manischewitz, J., Golding, H., et al. (2011). Broadly neutralizing human antibody that recognizes the receptorbinding pocket of influenza virus hemagglutinin. Proc. Natl. Acad. Sci. U.S.A. 108, 14216-14221. doi: 10.1073/pnas.1111497108

Winarski, K. L., Tang, J., Klenow, L., Lee, J., Coyle, E. M., Manischewitz, J., et al. (2019). Antibody-dependent enhancement of influenza disease promoted by increase in hemagglutinin stem flexibility and virus fusion kinetics. Proc. Natl. Acad. Sci. U.S.A. (2019) 116, 15194-15199. doi: 10.1073/pnas.18213 17116

Wohlbold, T. J., Chromikova, V., Tan, G. S., Meade, P., Amanat, F., Comella, P., et al. (2016). Hemagglutinin stalk- and neuraminidase-specific monoclonal antibodies protect against lethal $\mathrm{H} 10 \mathrm{~N} 8$ influenza virus infection in mice. J. Virol. 90, 851-861. doi: 10.1128/JVI.02275-15

Wohlbold, T. J., and Krammer, F. (2014). In the shadow of hemagglutinin: a growing interest in influenza viral neuraminidase and its role as a vaccine antigen. Viruses 6, 2465-2494. doi: 10.3390/v6062465

Wohlbold, T. J., Nachbagauer, R., Xu, H., Tan, G. S., Hirsh, A., Brokstad, K. A., et al. (2015). Vaccination with adjuvanted recombinant neuraminidase induces broad heterologous, but not heterosubtypic, cross-protection against influenza virus infection in mice. MBio 6:e02556. doi: 10.1128/mBio.02556-14

Wohlbold, T. J., Podolsky, K. A., Chromikova, V., Kirkpatrick, E., Falconieri, V., Meade, P., et al. (2017). Broadly protective murine monoclonal antibodies against influenza B virus target highly conserved neuraminidase epitopes. Nat. Microbiol. 2, 1415-1424. doi: 10.1038/s41564-017-0011-8

Yang, C., Skiena, S., Futcher, B., Mueller, S., and Wimmer, E. (2013). Deliberate reduction of hemagglutinin and neuraminidase expression of influenza virus leads to an ultraprotective live vaccine in mice. Proc. Natl. Acad. Sci. U.S.A. 110, 9481-9486. doi: 10.1073/pnas.1307473110
Yang, X., Steukers, L., Forier, K., Xiong, R., Braeckmans, K., Van Reeth, K., et al. (2014). A beneficiary role for neuraminidase in influenza virus penetration through the respiratory mucus. PLOS ONE 9:e110026. doi: 10.1371/journal.pone.0110026

Yassine, H. M., Boyington, J. C., McTamney, P. M., Wei, C. J., Kanekiyo, M., Kong, W. P., et al. (2015). Hemagglutinin-stem nanoparticles generate heterosubtypic influenza protection. Nat. Med. 21, 1065-1070. doi: 10.1038/nm.3927

Zhang, G. G., Li, D. X., Zhang, H. H., Zeng, Y. M., and Chen, L. (2009). Enhancement of mucosal immune response against the $\mathrm{M} 2 \mathrm{eHBc}+$ antigen in mice with the fusion expression products of LTB and $\mathrm{M} 2 \mathrm{eHBc}+$ through mucosal immunization route. Vet. Res. Commun. 33, 735-747. doi: 10.1007/s11259-009-9222-7

Zhang, J., Fan, H. Y., Zhang, Z., Zhang, J., Zhang, J., Huang, J. N., et al. (2016). Recombinant baculovirus vaccine containing multiple M2e and adjuvant LTB induces $\mathrm{T}$ cell dependent, cross-clade protection against $\mathrm{H} 5 \mathrm{~N} 1$ influenza virus in mice. Vaccine 34, 622-629. doi: 10.1016/j.vaccine.2015.12.039

Zheng, Z., Paul, S. S., Mo, X., Yuan, Y. A., and Tan, Y. J. (2018). The vestigial esterase domain of haemagglutinin of $\mathrm{H} 5 \mathrm{N1}$ avian influenza A virus: antigenicity and contribution to viral pathogenesis. Vaccines 6:53. doi: $10.3390 /$ vaccines 6030053

Conflict of Interest: The authors declare that the research was conducted in the absence of any commercial or financial relationships that could be construed as a potential conflict of interest.

Copyright (C) 2019 Jang and Seong. This is an open-access article distributed under the terms of the Creative Commons Attribution License (CC BY). The use, distribution or reproduction in other forums is permitted, provided the original author(s) and the copyright owner(s) are credited and that the original publication in this journal is cited, in accordance with accepted academic practice. No use, distribution or reproduction is permitted which does not comply with these terms. 